University of Wollongong

Research Online

Faculty of Engineering and Information

Faculty of Engineering and Information

Sciences - Papers: Part A

Sciences

$1-1-2014$

Bayesian space-time model to analyse frost risk for agriculture in Southeast Australia

Steven Crimp

CSIRO

Khandoker Shuvo Bakar

CSIRO

Phillip Kokic

University of Wollongong, Philip.Kokic@csiro.au

Huidong Jin

CSIRO

Neville Nicholls

Monash University

See next page for additional authors

Follow this and additional works at: https://ro.uow.edu.au/eispapers

Part of the Engineering Commons, and the Science and Technology Studies Commons

Research Online is the open access institutional repository for the University of Wollongong. For further information contact the UOW Library: research-pubs@uow.edu.au 


\title{
Bayesian space-time model to analyse frost risk for agriculture in Southeast Australia
}

\begin{abstract}
Despite a broad pattern of warming in minimum temperatures over the past 50years, regions of southeastern Australia have experienced increases in frost frequency in recent decades, and more broadly across southern Australia, an extension of the frost window due to an earlier onset and later cessation. Consistent across southern Australia is a later cessation of frosts, with some areas of southeastern Australia experiencing the last frost an average 4weeks later than in the 1960 s (i.e. mean date of last frost for the period 1960-1970 was 19 September versus 22 October for the period 2000-2009). We seek to model the spatial changes in frosts for a region exhibiting the strongest individual station trends, i.e. northern Victoria and southern New South Wales. We identify statistically significant trends at low-lying stations for the month of August and construct and validate a Bayesian space-time model of minimum temperatures, using rates of greenhouse gas (GHG) emissions, as well as other well-understood causal factors including solar radiation, the El Niño Southern Oscillation (ENSO 3.4) and times series data relating to the position (STRP) and intensity (STRI) of subtropical highs and blocking high pressure systems. We assess the performance of this modelling approach against observational records as well as against additive and linear regression modelling approaches using root mean square error (RMSE), mean absolute error (MAE), mean absolute percentage error (MAPE) as well as false alarm and hit rate metrics. The spatiotemporal modelling approach demonstrated considerably better predictive skill than the others, with enhanced performance across all the metrics analysed. This enhanced performance was consistent across each decade and for temperature extremes below $2^{\circ} \mathrm{C}$.
\end{abstract}

\section{Keywords}

frost, spatiotemporal modelling, synoptic scale drivers

\section{Disciplines}

Engineering | Science and Technology Studies

\section{Publication Details}

Crimp, S., Bakar, K., Kokic, P., Jin, H., Nicholls, N. \& Howden, M. (2015). Bayesian space-time model to analyse frost risk for agriculture in Southeast Australia. International Journal of Climatology, 35 (8), 2092-2108.

\section{Authors}

Steven Crimp, Khandoker Shuvo Bakar, Phillip Kokic, Huidong Jin, Neville Nicholls, and Mark Howden 


\title{
Bayesian space-time model to analyse frost risk for agriculture in Southeast Australia
}

\author{
Steven Crimp, ${ }^{\mathrm{a}, \mathrm{b} *}$ Khandoker Shuvo Bakar, ${ }^{\mathrm{a}}$ Philip Kokic, ${ }^{\mathrm{a}, \mathrm{c}}$ Huidong Jin, ${ }^{\mathrm{a}}$ Neville Nicholls ${ }^{\mathrm{b}}$ \\ and Mark Howden ${ }^{\mathrm{a}}$ \\ ${ }^{a}$ Climate Adaptation Flagship, CSIRO, Canberra, Australia \\ ${ }^{\mathrm{b}}$ Monash University, Clayton, Australia \\ ${ }^{\mathrm{c}}$ NIASRA, University of Wollongong, Australia
}

\begin{abstract}
Despite a broad pattern of warming in minimum temperatures over the past 50 years, regions of southeastern Australia have experienced increases in frost frequency in recent decades, and more broadly across southern Australia, an extension of the frost window due to an earlier onset and later cessation. Consistent across southern Australia is a later cessation of frosts, with some areas of southeastern Australia experiencing the last frost an average 4 weeks later than in the 1960s (i.e. mean date of last frost for the period 1960-1970 was 19 September versus 22 October for the period 2000-2009). We seek to model the spatial changes in frosts for a region exhibiting the strongest individual station trends, i.e. northern Victoria and southern New South Wales. We identify statistically significant trends at low-lying stations for the month of August and construct and validate a Bayesian space-time model of minimum temperatures, using rates of greenhouse gas (GHG) emissions, as well as other well-understood causal factors including solar radiation, the El Niño Southern Oscillation (ENSO 3.4) and times series data relating to the position (STRP) and intensity (STRI) of subtropical highs and blocking high pressure systems. We assess the performance of this modelling approach against observational records as well as against additive and linear regression modelling approaches using root mean square error (RMSE), mean absolute error (MAE), mean absolute percentage error (MAPE) as well as false alarm and hit rate metrics. The spatiotemporal modelling approach demonstrated considerably better predictive skill than the others, with enhanced performance across all the metrics analysed. This enhanced performance was consistent across each decade and for temperature extremes below $2{ }^{\circ} \mathrm{C}$.
\end{abstract}

KEY WORDS frost; spatiotemporal modelling; synoptic scale drivers

Received 2 August 2013; Revised 10 June 2014; Accepted 24 June 2014

\section{Introduction}

Assessments of the changing nature of frost occurrence in Australia have used high-quality temperature recording station data and examined changes in the number of frosts between 1960 and present (Kalma et al., 1992; Stone et al., 1996; Collins et al., 2000; Karoly and Wu, 2005; Alexander et al., 2006a, 2006b). Common results from these studies include statistically significant increasing trends in the incidence of cold nights and frosts since the 1960s particularly across the southern parts of New South Wales (NSW) and Victoria. The most recent analyses posted by the Australian Bureau of Meteorology in 2012, based on the Australian Climate Observations Reference Network - Surface Air Temperature (ACORN-SAT), derived from 112 high-quality recording stations (Trewin, 2012), show that while mean minimum temperatures have been increasing over Australia, the number of extreme cold temperature events (i.e. screen temperatures below $2^{\circ} \mathrm{C}$ ) has increased on-average by 4 events per decade since 1970

* Correspondence to: S. Crimp, Climate Adaptation Flagship, CSIRO, GPO Box 1700, Canberra ACT 2601, Australia. E-mail: Steven.Crimp@csiro.au over much of Victoria and NSW. This apparent 'paradox' of minimum temperature warming but increasing frost extremes is of significant concern to various agricultural industries (Anderson and Garlinge, 2000).

The links between frost and crop production are well understood and have been extensively reported (Sakai and Larcher, 1987; Coleman, 1992; Kalma et al., 1992; Davidson, 1997; Porter and Gawith, 1999; Rogiers, 1999; Cashman, 2000; Woldendorp et al., 2008; Budong et al., 2010). While frost damage in cereals is dependent on issues such as crop tolerance, growth stage, moisture content of the soil, duration of the subfreezing temperature and location in the field, it is widely agreed that damage is most severe once the 'head' or 'ear' has emerged (Livingston and Swinbank, 1950; Single, 1964; Afanasev, 1966; Paulsen and Heyne, 1983). In terms of cereal production, frost occurrence during late Austral winter and Austral spring (i.e. August-November) is most significant in terms of crop damage and resultant loss of productivity. To lower the risk of frost damage, producers often plant crops later in the sowing window (i.e. late April-June), so heading and grain development occur when warmer temperatures prevail towards the end of the frost window. While this approach does serve to lower the risk of exposure to frosts, 
it does expose the crop, instead, to increased likelihood of drought and high temperature conditions during grain filling, potentially reducing the yield (Passioura, 2007). For this reason, historical frost occurrence in Australia has contributed significantly to the distribution of agricultural land use as seen in Australia today.

Frost damage is estimated to cost Australian agricultural producers between $\$ 120$ and $\$ 700$ million in lost revenue each year (Blennow and Lindkvist, 2000; Vaneckova et al., 2010; Pouteau et al., 2011). For example, in Victoria in 2006, over half the annual fruit production was lost in response to a single event totalling $\$ 500$ million in lost revenue (ABARE, 2007). In the same year, $\$ 90$ million of damage was recorded in the Western Australia wheat growing region (ABARE, 2007).

The examination of climatic variability and associated climate drivers has been undertaken using both statistical inference and dynamic simulation. To date, statistical studies have considered linear and nonlinear type regression approaches to characterize the variation over time (Schubert, 1998; Fowler et al., 2007; Vaneckova et al., 2010; Frost et al., 2011). Over time these statistical approaches have been developed to capture the seasonal variability in the data, e.g. the basic structural time series model (Harvey, 1989). There are also a number of examples of research that use dynamic state-space modelling approaches for analysing climatic data (Kokic et al., 2011). These models are useful to obtain trends, get predictions of the future and assess the influence of covariates; however, the current approaches are not able to explain spatial variation. That is, they do not consider any spatial and/or spatiotemporal dependency between data even though this clearly occurs (Sahu et al., 2007). Alternative approaches that do consider these dependencies include advanced Bayesian space-time modelling (Cressie and Wikle, 2011). These types of models have been successfully applied in air pollution studies (Sahu et al., 2007; Sahu and Bakar, 2012a, 2012b; Bakar and Sahu, 2013) and demonstrate that when these dependencies are accounted for the predictive performance of the models is improved.

In this article, Bayesian space-time modelling is used to obtain predictive spatial distribution information of frost occurrence across northern Victoria and southern NSW. We assess the performance of this modelling approach against observational records as well as against linear and additive regression models (Hastie and Tibshirani, 1999; Wood, 2006) that are frequently used in modelling climatic variables and species distribution models (Ashcroft et al., 2008; Dukic et al., 2012; Kivinen et al., 2012; O'Neill et al., 2012; Tong et al., 2012). This is undertaken in order to compare the predictive power of the three approaches and highlight the importance of spatial dependency. We examine the behaviour and interaction of the causal factors across decades and use the approach to examine spatial and temporal changes in the incidence of extreme minimum temperatures in unmonitored locations in this region.

This article contributes to the applied climatology research domain in four ways: (1) to contribute to the understanding of the changing pattern of frost occurrence across the Australian case study region (northern Victoria and southern NSW) for the period 1960 to present; (2) to predict changes in variability in frost occurrence both temporally and spatially and compare the results with the limited independent observational data for this region; (3) to provide estimates of changes in frost frequency for unmonitored locations within the case study region using spatiotemporal correlations derived from the Bayesian approach and (4) to compare this spatiotemporal model with commonly used linear and additive regression models.

\section{Data and methods}

The statistical modelling and subsequent analyses were undertaken in the $\mathrm{R}$ programming language ( $\mathrm{R}$ Development-Core-Team, 2006) using the spTimer package developed by Bakar and Sahu (2013). Use of this software allows the development of Bayesian space-time models (Cressie and Wikle 2011) using a number of indices of climate variables known to have a physical link to frost occurrence and frequency. The $\mathrm{R}$ package spTimer was used to analyse daily minimum temperature and hence to obtain patterns and predictions of frost occurrence. This approach allows the modelling of observations in off-observation site locations based on posterior information obtained from the model fitted to data at observation site locations.

\subsection{Temperature data}

The baseline minimum temperature datasets used for this study were sourced from the Australian Bureau of Meteorology and are both the high quality (HQ) gridded as well as individual station minimum temperature data across northern Victoria and southern NSW (Trewin, 2012). Minimum temperature data was available from a total of 75 locations across the study region, including seven HQ stations for the period 1961-2009 (Figure 1). Twenty-five sites were randomly selected to serve as validation sites upon which a series of statistical analyses were performed (the results presented later in this article).

For the purposes of this analysis, the occurrence of frost was assumed to occur once daily minimum temperatures fell below $2^{\circ} \mathrm{C}$ (Kalma et al., 1992). Given the relative impact of frost on Australian agriculture is most significant during late winter and spring, the period August-November became the reference period over which all analyses were conducted.

\subsection{Other climatic variables and indices}

A focus of this study was to examine the spatial changes in frost occurrence over time and to understand the drivers of this change. To achieve this, we developed a Bayesian spatial-temporal statistical model using rates of greenhouse gas (GHG) emissions, as well as other well-understood causal factors including solar radiation, the El Niño Southern Oscillation (ENSO), times series data relating to the position (STRP) and intensity 


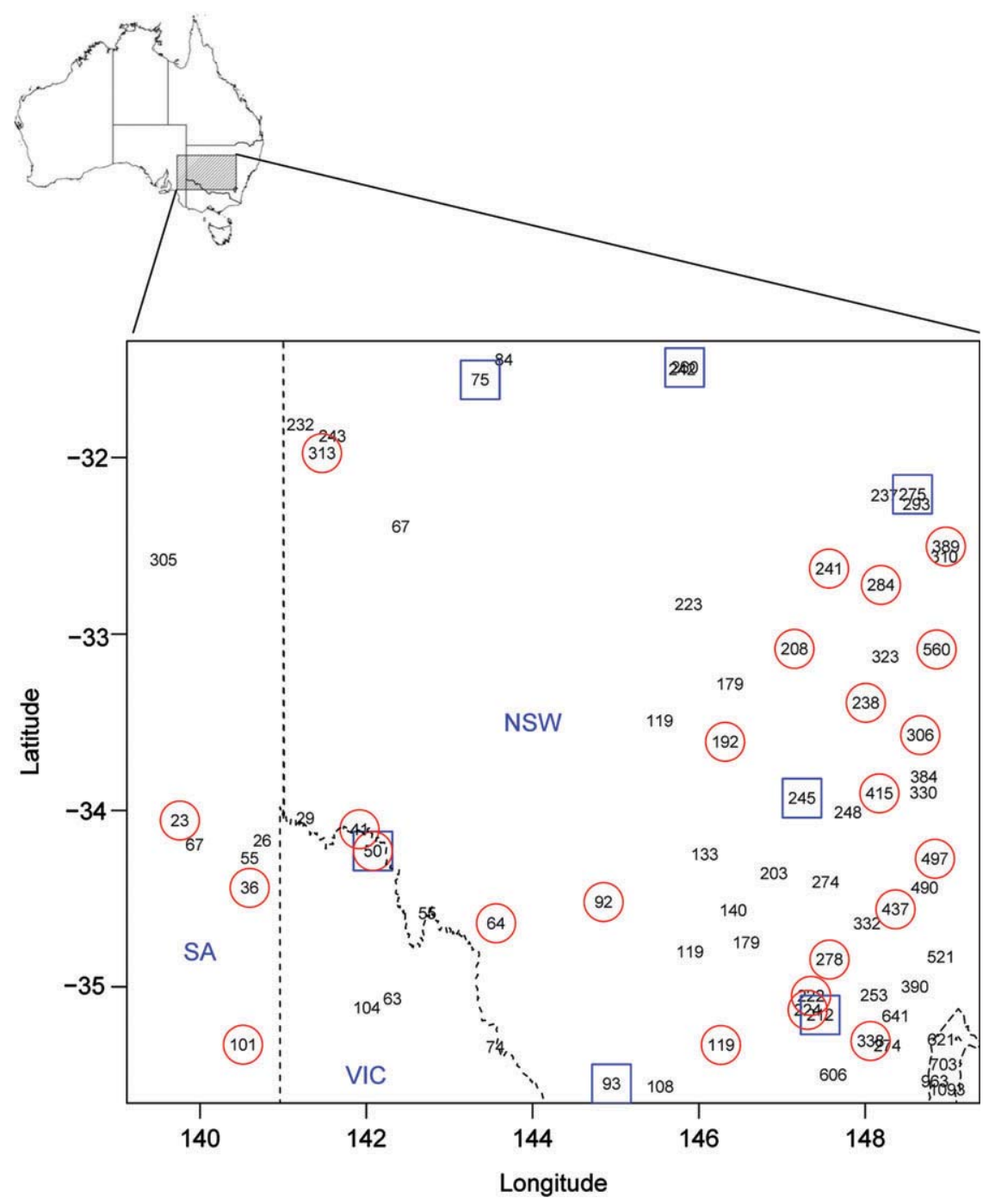

Figure 1. A total of 75 locations are used in this study. Each location is marked with its corresponding elevation presented in metres. A total of 25 sites were chosen randomly as validation sites (circles). The seven HQ locations are marked as squares.

(STRI) of subtropical highs and a measure of atmospheric blocking (BI). These were introduced into the model as a series of covariates to explore their influence on minimum temperatures. These covariate data were obtained from a variety of sources as presented in Table 1. Some of these data required post-processing to ensure consistency of record length and data frequency.

Large-scale changes in Australian temperature and rainfall have been well documented over the last 30 years, with changes in these variables linked to variations in large-scale mean Sea Level Pressure (SLP) (Nicholls et al., 1996, Nicholls, 2010; Timbal and Fawcett, 2013; Whan et al., 2014), shifts in synoptic systems (Hope, 2006; Risbey et al., 2009), changes in baroclinicity (Frederiksen and Frederiksen, 2007), the Southern Annular Mode (SAM) (Cai and Cowan, 2006), natural variability on a range of timescales (Cai et al., 2005; Cai and Cowan 2008; Ummenhofer et al., 2011; Jones et al., 2012), land cover changes (Timbal and Arblaster, 2006) and anthropogenic forcing (Karoly and Braganza, 2005; Cai and Cowan, 2006; Preston and Jones, 2006).
Changes in rainfall and temperature have well-documented links to changes in frost frequency, duration and intensity (Plummer et al., 1999; Hughes, 2003; Levy et al., 2004; Murphy and Timbal, 2008; Battisti and Naylor, 2009; Timbal and Fawcett, 2013). Thus drivers of seasonal, decadal and multi-decadal variation in rainfall and temperature have been used as parameters to develop the statistical modelling of minimum temperature extremes.

The historical trajectory of GHG accumulation in the atmosphere is well established as an important driver of change in Australian historical temperature and rainfall (Karoly and Braganza, 2005; Hope, 2006; Jones et al., 2012). As both these variables are strongly correlated with frost occurrence, we have included this as a model covariate (i.e. $\mathrm{fCO}_{2}$ ). In this application, we have considered equivalent carbon dioxide $\left(\mathrm{eCO}_{2}\right)$ as a model parameter as it represents a combined measure of all major GHGs controlled under the Kyoto protocol calculated using carbon dioxide radiative forcing relationships integrated with the effects of aerosols and particulates 
Table 1. Covariate data used for statistical modelling of minimum temperatures for the northern Victoria and southern New South Wales case study region.

\begin{tabular}{|c|c|c|c|c|}
\hline Time series & Forcing & Source & Time period & Frequency \\
\hline $\begin{array}{l}\mathrm{eCO}_{2} \\
\text { (Clarke } \text { et al., 2007) }\end{array}$ & Major GHGs & $\begin{array}{l}\text { RCP database (version 2): } \\
\text { http://www.iiasa.ac.at/web-apps/ } \\
\text { tnt/RcpDb }\end{array}$ & $1960-2009$ & Annual (mid-year) \\
\hline $\begin{array}{l}\text { ENSO } 3.4 \\
\text { (Allan and Haylock } \\
\text { 1993) }\end{array}$ & $\begin{array}{l}\text { Equatorial Pacific Ocean } \\
\text { SSTs }\end{array}$ & $\begin{array}{l}\text { Australian Bureau of Meteorology: } \\
\text { http://www.bom.gov.au/climate/ } \\
\text { enso/indices.shtml }\end{array}$ & 1960-2009 & Weekly \\
\hline $\begin{array}{l}\text { SOI } \\
\text { (Allan and Haylock } \\
\text { 1993) }\end{array}$ & ENSO & $\begin{array}{l}\text { Australian Bureau of Meteorology: } \\
\mathrm{ftp} / / \mathrm{ftp} . \text { bom.gov.au/anon/home/ncc/ } \\
\text { www/sco/soi/soiplaintext.html }\end{array}$ & $1960-2009$ & Monthly \\
\hline $\begin{array}{l}\text { fS } \\
\text { (Wang et al., 2011) }\end{array}$ & $\begin{array}{l}\text { Daily solar radiation flux } \\
\text { data }\end{array}$ & $\begin{array}{l}\text { National Center for Environmental } \\
\text { Prediction (NCEP): } \\
\text { http://www.esrl.noaa.gov/psd/cgi-bin/ } \\
\text { db_search/DBSearch.pl?Dataset=NCEP } \\
\text { +Reanalysis+Daily+Averages+ } \\
\text { Other+Gaussian+Grid\&Variable= } \\
\text { Downward+solar+radiation+flux\& } \\
\text { group=0\&submit=Search }\end{array}$ & 1960-2009 & Daily \\
\hline $\begin{array}{l}\text { STRP } \\
\text { Drosdowsky (2005) } \\
\text { and later by Larsen } \\
\text { and Nicholls (2009) }\end{array}$ & Subtropical ridge position & $\begin{array}{l}\text { Derived from the formulation by Larsen } \\
\text { and Nicholls (2009) using Mean Sea } \\
\text { Level Pressure Data from The National } \\
\text { Centers for Environmental } \\
\text { Prediction-National Center for } \\
\text { Atmospheric Research (NCEP-NCAR) } \\
\text { climate reanalysis (Reanalysis 2) dataset: } \\
\text { http://www.esrl.noaa.gov/psd/data/ } \\
\text { gridded/data.ncep.reanalysis2.surface. } \\
\text { html }\end{array}$ & 1960-2009 & Monthly \\
\hline $\begin{array}{l}\text { STRI } \\
\text { Drosdowsky (2005) } \\
\text { and later by Larsen } \\
\text { and Nicholls (2009) }\end{array}$ & $\begin{array}{l}\text { Subtropical Ridge } \\
\text { intensity }\end{array}$ & $\begin{array}{l}\text { Derived from the formulation by Larsen } \\
\text { and Nicholls (2009) using Mean Sea } \\
\text { Level Pressure Data from The National } \\
\text { Centers for Environmental } \\
\text { Prediction-National Center for } \\
\text { Atmospheric Research (NCEP-NCAR) } \\
\text { climate reanalysis (Reanalysis 2) dataset: } \\
\text { http://www.esrl.noaa.gov/psd/data/ } \\
\text { gridded/data.ncep.reanalysis2.surface } \\
\text {.html }\end{array}$ & 1960-2009 & Monthly \\
\hline Elevation & Elevation & $\begin{array}{l}\text { Station elevation data derived from } \\
\text { climate station meta-data. Station data } \\
\text { extracted from http://www.bom.gov. } \\
\text { au/climate/data/ }\end{array}$ & 1960-2009 & NA \\
\hline $\begin{array}{l}\text { BI } \\
\text { (Pook et al., 2013) }\end{array}$ & Blocking Index & $\begin{array}{l}\text { Based on the Australian Bureau of } \\
\text { Meteorology formulation (Pook and } \\
\text { Gibson, 1999) Vector wind data sourced } \\
\text { from the National Center for } \\
\text { Environmental Prediction (NCEP) }\end{array}$ & 1960-2009 & Monthly \\
\hline
\end{tabular}

(Gohar and Shine, 2007). To conform to the approximate physical relationship between GHG concentration and temperature, $\mathrm{eCO}_{2}$ was converted to a radiating forcing value using the approximation $\mathrm{fCO}_{2} \equiv f\left(\mathrm{eCO}_{2}\right)=5.35$ $\log _{\mathrm{e}}\left(\mathrm{eCO}_{2} / 278\right)$ (Myhre et al., 1998).

The work of Stone et al. (1996) highlighted the large variations in frost frequency between El Niño, La Niña and ENSO-neutral years in Australia with other research (Allan and Haylock, 1993; Chase et al., 2003; Murphy and Timbal, 2008; Pezza and Ambrizzi, 2005) confirming this influence as well as highlighting further global teleconnections. For this reason, we include a time series of mean sea surface temperatures from the NINO 3.4 region (i.e. ENSO 3.4) as well as the Southern Oscillation Index (SOI) in our model in order to capture both a faster (atmospheric) and slower (oceanic) moving influence on frost from the Pacific ocean-atmosphere system (Figure 2). SOI is not included in Section 3 as it was found statistically insignificant as a covariate for the period of analysis presented here (i.e. August).

Other covariates considered in the statistical model include a measure of atmospheric blocking to the south of 


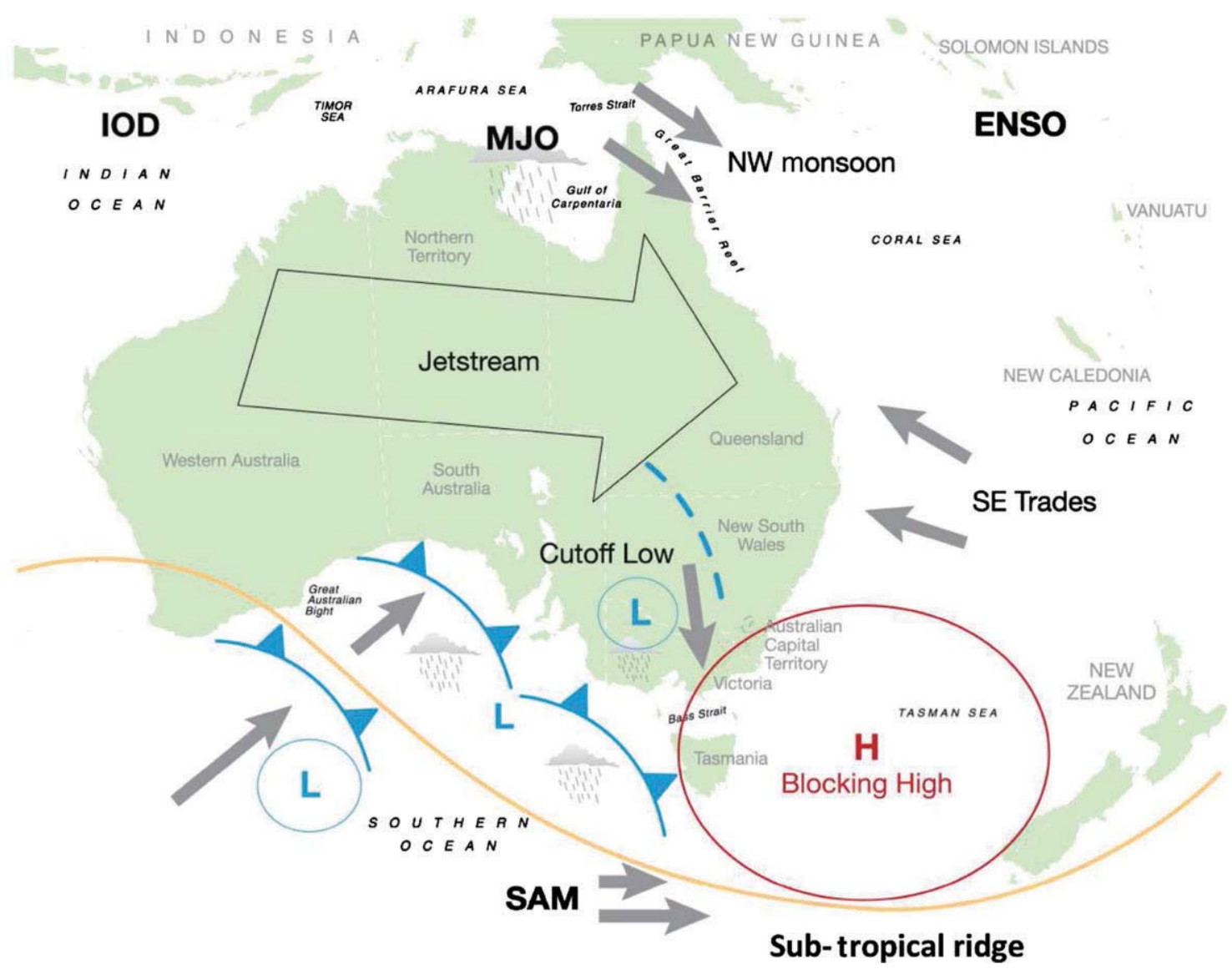

Figure 2. A map indicating the relative location of major drivers of rainfall and temperature variation (after Risbey et al., 2009).

Australia (BI), subtropical ridge (STR) indices (Figure 2), volcanic forcing indices as well as measures of sun spot activity. The BI is an index of air pressure calculated from the pressure gradient between mid and high latitudes of the Southern Hemisphere and has been found to have a strong influence on temperature (Pezza and Simmonds, 2005; Cattiaux et al., 2010; Barnes et al., 2012). Regional sea level pressure indices that measure the position and intensity of the subtropical ridge (STRP - position; STRI - intensity) are derived from formulations by Drosdowsky (2005) and later by Larsen and Nicholls (2009). Volcanic forcing indices and measures of sun spot activity are not included in the modelling or reported in Section 3 as they too were found statistically insignificant.

In terms of the BI, monthly mean data are available at $2.5^{\circ}$ resolution for easting positions across the entire hemisphere. For the purposes of this study, we focus on using data from 137.5 to $150^{\circ} \mathrm{E}$, due to strong correlations against southern Australian minimum temperatures compared with other longitudes either side of this range (Figure 2). Daily solar radiation flux data (fS) were obtained from the National Center for Environmental Prediction (NCEP) for the period 1960-2009. The gridded temperature and solar flux data were spatially misaligned and so a kriging technique (Krige, 1951; Cressie, 1993; Banerjee et al., 2004; Diggle and Ribeiro, 2007) was employed to rectify this issue.
We undertook a series of analyses to check whether rainfall or 1-month-lagged rainfall should be included as a covariate in the spatiotemporal modelling approach. The inclusion resulted in declines in model performance in terms of spatial predictive power, i.e. Predictive Model Choice Criteria (PMCC). An analysis of correlation between variables showed that rainfall was strongly correlated with ENSO 3.4, the blocking index (BI) and STRI. So including rainfall could also result in over-specification of the model. As a result of these analyses this covariate was not included.

Most covariates are introduced as monthly mean values in the Bayesian spatial-temporal approach; thus for each location, a combination of monthly covariates and daily temperature data is used.

\subsection{Exploratory analysis}

We analysed daily data for 122 days in every year during August-November, from 1961 to 2009 across all 75 stations in the case study region. This allows a formal evaluation of minimum temperature variation and hence changes in frost occurrence. The exploratory analyses consist of a total of 448350 observations of minimum temperature with only $0.71 \%$ missing. Using linear regression analysis, $39.3 \%$ of the 75 stations demonstrated increasing frost frequency over the last 49 years and $34 \%$ showed declining trends in frost occurrence. The remaining $26 \%$ 


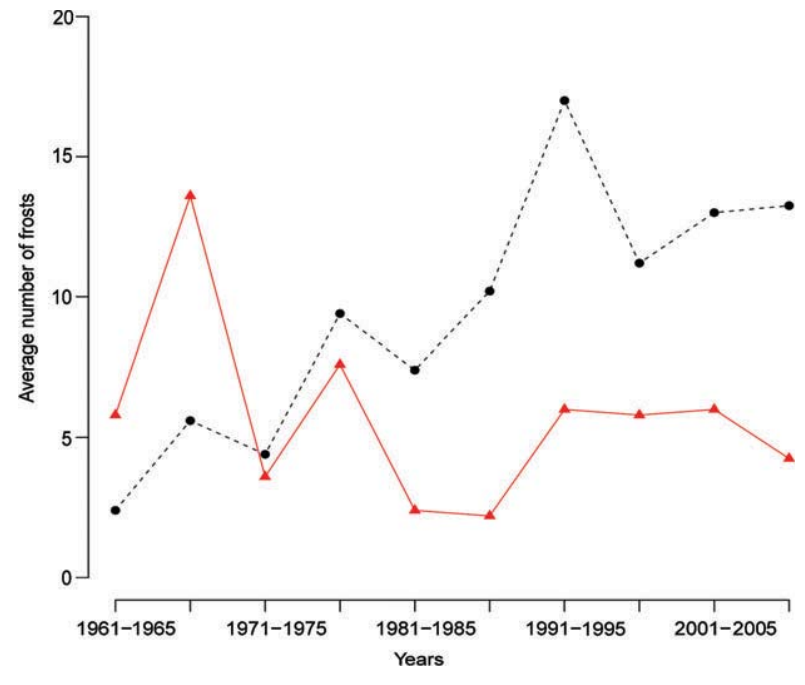

Figure 3. Five-year average frosts for two randomly chosen locations that show upward and downward trends in frost levels over time.

demonstrated no significant trend. Figure 3 provides a 5-year running mean of frost occurrence for two indicative locations in the study region. This highlights that the occurrence of frost varies spatially and also provides a basis for using a Bayesian space-time modelling approach.

Table 2 shows the average number of frosts for different decades and months. When examining all the months from August to November, the mean number of frosts per month across the case study region was 3.33 for the period 1961-2009. In the earlier part of the record (i.e. 1961-1970), the mean number of frosts was 3.71. This mean value declined over the next two decades followed by an increase since 1991. However, when we separate out the frost occurrence into the individual months we observe the mean frost numbers in August increased to 9.01 in 2001-2009 compared to 8.59 in 1961-1970.

We also obtain average frost levels based on different elevations for different decades. We divide all 75 locations into four groups based on their elevations (Figure 1). For locations with elevation of $\leq 100 \mathrm{~m}$, there is a marked increase over time in the mean number of frosts for the August-November period. Other sites demonstrate a decline in frost numbers to 1990 and then a recovery in frost numbers to 2009, although at lower levels to the earlier part of the record. If the declines were entirely related to anthropogenic warming, then we would expect to see comparable reductions in frost risk at all elevations. If we take into account the observed changes in synoptic circulation as identified by Nicholls et al. (1996), Nicholls (2010), Timbal and Fawcett (2013) and Whan et al. (2014) (i.e. southerly displacement and intensification of the subtropical ridge), then we expect warming to be associated with both an increase in the advection of cold air, associated with high-pressure system southerly migration and intensification, but also an increase in wind speed associated with the intensification. This is supported by increases in meridional wind speeds since the mid-1970s as observed by Verdon-Kidd et al. (2013). Given the significant increase in frost risk in August and at sites $\leq 100 \mathrm{~m}$ above sea level, as well as the importance of frost occurrence at this time, in terms of significant crop damage and resultant loss of productivity, the validation and predictive information presented in Section 3 is based on the month of August (Table 3).

\subsection{Models}

Initial development of our statistical models was based on the entire minimum temperature record for the case study region. From this we were able to obtain the frequency of events below $2^{\circ} \mathrm{C}$. To test the performance of this model, we compared it against two other statistical modelling approaches namely, linear regression model and an additive model. To compare the performance of the three modelling approaches, we use minimum temperature data from 50 locations to fit the models and the remaining 25 locations were set aside for validation purpose, see Figure 1. These 25 locations were chosen randomly to avoid purposive bias in the prediction and validation. However, for subsequent overall prediction in the region and producing the frost risk maps provided in Section 3.3., we have used all 75 locations.

For each type of model, we fit six separate sets of models. Initially, we modelled the full dataset containing 50 randomly chosen locations from 1961 to 2009 . We then fit models separately for each decade starting from 1961 (i.e. 1961-1970 for the 50 locations and then validated those in the 25 set aside locations for the same period). We also fitted models for the decades 1971-1980, 1981-1990, 1991-2000 and 2001-2009 in order to track changes in correlations of the covariates with minimum temperatures across decades. The rationale for producing individual decadal models was that while decadal variation in covariate values can be determined by fitting the

Table 2. Average number of frost days in each month based on different decades.

\begin{tabular}{lcccrr}
\hline \multirow{2}{*}{ Months } & \multicolumn{3}{c}{ Average number of frosts } \\
\cline { 2 - 6 } & August & September & October & November & All \\
\hline Decade: $1961-1970$ & 8.59 & 4.76 & 1.21 & 0.30 & 3.71 \\
Decade: $1971-1980$ & 8.65 & 4.04 & 0.91 & 0.25 & 3.46 \\
Decade: $1981-1990$ & 6.08 & 3.31 & 0.99 & 1.10 & 2.63 \\
Decade: $1991-2000$ & 8.96 & 3.27 & 0.92 & 0.16 & 3.34 \\
Decade: $2001-2009$ & 9.01 & 3.82 & 1.10 & 0.21 & 3.52 \\
Year: $1961-2009$ & 8.24 & 3.84 & 1.02 & 3.33 \\
\hline
\end{tabular}


Table 3. Average number of frost days for different elevations based on different decades for all 75 locations.

\begin{tabular}{lccccc}
\hline Elevation (in m) & \multicolumn{5}{c}{ Average number of frosts for different elevations } \\
\cline { 2 - 5 } & $\leq 100$ & $100-200$ & $200-300$ & $>300$ & All \\
\hline Number of locations & 17 & 13 & 22 & 23 & 75 \\
Decade: 1961-1970 & 22.17 & 30.90 & 74.15 & 151.32 & 278.55 \\
Decade: 1971-1980 & 18.62 & 28.52 & 74.62 & 138.07 & 259.85 \\
Decade: 1981-1990 & 13.47 & 18.75 & 50.15 & 115.20 & 197.57 \\
Decade: 1991-2000 & 31.72 & 28.50 & 67.20 & 123.85 & 250.27 \\
Decade: 2001-2009 & 32.89 & 25.44 & 68.92 & 136.86 & 264.11 \\
Year: 1961-2009 & 23.59 & 26.24 & 66.97 & 132.98 & 249.79 \\
\hline
\end{tabular}

Bayesian space-time model across the whole time period (i.e. 1961-2009), as this is not possible for either the linear or additive approaches. To allow effective comparisons across the three approaches model performance was assessed at the decadal scale. Hence for three types of models, we fit a total of 18 models and compare their performance in Section 3.2.

The variables discussed in Section 2.2. are used as covariates in all the models. In the subsection that follows we provide a brief summary of how the climatic variables and indices were used for all models.

Let $Y_{l}\left(s_{i}, t\right)$ be the observed minimum temperature at location $s_{i}, i=1, \ldots, n$ and at two nested time points $t, t=1, \ldots, T$ and $l, l=1, \ldots, r$. For example, in our study we model $T=122$ days in each year for $r=49$ years; $T=31$ when we focus only on August. We write the model as:

$$
Y\left(s_{i}, t\right)=\mu\left(s_{i}, t\right)+\epsilon\left(s_{i}, t\right)
$$

where $\epsilon\left(s_{i}, t\right)$ is the white noise of the model following a Gaussian distribution with mean zero and variance $\sigma_{\epsilon}^{2}$. The term $\mu\left(s_{i}, t\right)$ is the mean process of the model. Let $\boldsymbol{Y}_{l t}=\left[Y_{l}\left(s_{1}, t\right), \ldots, Y_{l}\left(s_{n}, t\right)\right]^{\prime}, \boldsymbol{\mu}_{l t}=\left[\mu_{l}\left(s_{1}, t\right)\right.$, $\left.\ldots, \mu_{l}\left(s_{n}, t\right)\right]^{\prime}$ and $\epsilon_{l t}=\left[\epsilon\left(s_{1}, t\right), \ldots, \epsilon\left(s_{n}, t\right)\right]^{\prime}$.

\subsubsection{Linear regression model}

Without considering any spatial effect, we define the mean process of a simple linear regression model as:

$$
\mu_{l t}=\xi_{k} 1+X_{l t} \beta
$$

where, $\boldsymbol{\xi}_{\boldsymbol{k}}$ is the decadal effect, $k=1, \ldots, 5$; and $\mathbf{1}$ is the $n \times 1$ vector of the decadal identifiers. In this article, for fitting a full model we consider $\xi_{1}$ represents the identity of the decade 1961-1970, $\boldsymbol{\xi}_{2}$ as the decade 1971-1980 and so on. Model Equation (2) is fitted with pooled dataset across the region.

We also fit Equation (2) on datasets obtained from each decade separately, where for example for 1961-1970, we use $l=10, t=122$ in each $l$ and the intercept as $\xi_{k}, k=1$. Similarly we fit separate models for the decades 1971-1980, 1981-1990, 1991-2000 and 2001-2009. Note that for models fitted with all years of data we consider $k=1, \ldots 5$ pooled in one model as stated in Equation (2). The term $\boldsymbol{X}_{l t}$ contains the design matrix of order $n \times p$, where $p=7$ (covariates we describe in
Section 2.2.), and $\boldsymbol{\beta}$ represents corresponding parameters of the covariates.

\subsubsection{Additive model}

We also consider the additive model where latitude and longitude positions are included using a smooth spline function. This type of model is nonlinear in nature and has some ability to use the spatial information via coordinate information. Thus, we write Equation (2) for the additive model as:

$$
\mu_{l t}=\xi_{k} 1+X_{l t} \beta+s(\text { lon, lat })_{l t}
$$

where $s$ (lon, lat) ${ }_{l t}$ represents the smooth spline function based on the longitude and latitude of the data points to reflect some spatial dependency. Hence, we write

$$
s(\text { lon, lat })=\sum_{j=1}^{K} \gamma_{j} \boldsymbol{b}_{j}(u, v)
$$

where $\boldsymbol{b}_{j}(u, v)$ is the known basis function with lon $=u$ and lat $=v$; and $\gamma_{j}$ is the unknown parameter that is estimated using penalized likelihood approach. For more details on the basis functions and estimation procedure, see Wood (2006, Section 4.1). Note that the additive model in Equation (3) has not been optimized for any covariates except spatial dependency.

\subsubsection{Bayesian space-time model}

The space-time model used in this study has a Bayesian structure and includes both spatial and temporal correlation. We use the same structure as given in Equation (1) and model the mean processes with a spatiotemporal random effect $\eta_{l}\left(s_{i}, t\right)$ at site $s_{i}$, and time $l$ and $t$. Let $\eta_{l t}=\left[\eta_{l}\left(s_{1}, t\right), \ldots, \eta_{l}\left(s_{n}, t\right)\right]^{\prime}$, hence we write:

$$
\mu_{l t}=\xi_{k} 1+X_{l t} \beta+\eta_{l t}
$$

where $\boldsymbol{\eta}_{\boldsymbol{l}}$ follows a Gaussian process with mean zero and covariance function of a Matern class correlation function (Banerjee et al., 2004; Diggle and Ribeiro, 2007; Cressie and Wikle, 2011) to describe spatial dependency. Under the Bayesian paradigm, we also need to define prior distributions of the model parameters; this is discussed in Section 2.4.4. 


\subsubsection{Space-time covariance, prior and posterior distributions}

The Matern function is useful for modelling a wide variety of spatial-temporal data as its smoothness and decay parameters can be easily estimated from the data. In this article, we use a special case of Matern function where the smoothness parameter is set to 0.5 , which is also known as the exponential covariance function (Banerjee et al., 2004). We estimate the space-time model using a Bayesian paradigm; prior information from the model parameter is used to obtain the posterior distribution. For posterior inference, we use the Gibbs sampling algorithm with 5000 runs. This Markov Chain Monte Carlo (MCMC) approach converges after 1000 iterations; hence, we discard the first 2000 samples as burn-in (Gelman, 2004). We also used multiple parallel runs and calculated the Gelman and Rubin statistics (Gelman and Rubin, 1992).

The full Bayesian model requires specifying prior distributions for all the unknown parameters in the model. We work with the inverse of the variance components and assume an independent gamma prior distribution with parameters $a$ and $b$ having mean $a / b$. In our implementation, we used $a=2$ and $b=1$ implying that these variance components have a prior mean of 1 and infinite variance. We assign a flat Gaussian prior with mean zero and large variance (10000) for the regression coefficients. For the spatial decay parameter, we assume an independent Gamma prior distribution in $(a, b)$ corresponding to approximate spatial ranges of $0-1000 \mathrm{~km}$. This range adequately covers our study region of interest.

A number of sensitivity analyses were performed in order to select prior distributions of parameters. We found our model is not sensitive to different sets of hyperparameters of the prior distributions, and thus detailed results are omitted for brevity.

\subsection{Model validation}

To check and validate the model performances, we used standard validation criteria, e.g. root mean square error (RMSE), mean absolute error (MAE), mean absolute percentage error (MAPE), false alarm and hit rate (Sahu and Bakar, 2012b) (see Table 2). Values of RMSE, MAE and MAPE close to zero imply that the model is robust, closely aligned with the observations and suitable for predictive use. False alarm and hit rates were calculated using a threshold of $2{ }^{\circ} \mathrm{C}$ consistent with the threshold temperature set for surface frost occurrence. A hit rate exceeding $70 \%$ and false alarm rate of $30 \%$, or lower, imply that the model is effective in predicting specific frost events.

\subsection{Computational issues}

For computational purposes in this study, we use the spTimer package (Bakar and Sahu, 2013) in R language (R-Development-Core-Team, 2006). This software allows us to fit data using Bayesian space-time models. We can also spatially predict observations in off-observation locations based on posterior information obtain from the model fitted to observation site locations (i.e. climate station sites). To fit and predict with the additive models, we use R package $m g c v$ (Wood, 2012).

\section{Results}

In this section, we provide results obtained from the statistical modelling undertaken across the whole time period 1961-2009, each decade and three modelling approaches (i.e. 18 sets of models in total).

\subsection{Parameter estimates}

Each of the covariates has been standardized over the entire 1961-2009 time period. The resultant standardization means that one can interpret the regression coefficients as the expected change of minimum temperature in degrees Celsius per one standard deviation change in the original (non-standardized) covariate that it represents, conditional on the other covariates in the model. For example, a coefficient estimate of -0.5 means that if the original covariate increased by one standard deviation and the other covariates were held fixed, then the minimum temperature would decrease by $0.5^{\circ} \mathrm{C}$.

Estimates of each parameter's contribution to minimum temperature variability were assessed across each decade and all years (i.e. 1961-2009) via statistical analysis of 3000 simulations of the space-time model (Figure 4). Median, interquartile range, as well as 10th and 90th percentile statistics were derived for each parameter and highlight the contribution made by each parameter to minimum temperatures (Figure 4). Superimposed solid circles and squares represent point estimates of the parameters for both the linear and additive models, respectively (Figure 4). Unsurprisingly the pattern of decadal variation for the six covariates is similar across the three models, although for the linear and additive models the parameter estimate values are more negatively weighted for the STRI and solar forcing covariates and more positively weighted for the STRP covariate (Figure 4). The more emphatic parameter estimates from both the linear and additive models are most likely the result of potential model bias as these fixed effect models do not consider variation in spatial correlation (Hodges and Reich, 2010).

Of the six covariates used to develop the statistical models, BI, STRI and solar forcing resulted in simulated median declines in minimum temperature of 1.25 , 2.46 and solar $0.47^{\circ} \mathrm{C}$, respectively $(p=0.01)$, across all years. The ENSO 3.4, STRP and $\mathrm{CO}_{2}$ forcing covariates resulted in simulated median increases in minimum temperatures of $0.22,1.47$ and $0.51{ }^{\circ} \mathrm{C}(p=0.01)$ respectively, across all years (Figure 4 ). Some variation in the extent of temperature change was simulated between decades, although the direction of temperature change remained either negative for the BI, STRI and solar forcing or positive for STRP and $\mathrm{CO}_{2}$ forcing (Figure 4). The ENSO 3.4 covariate resulted a greater degree of change in simulated minimum temperatures with a median change of $-0.26^{\circ} \mathrm{C}$ for the period $2001-2009$ as opposed to median increases in minimum temperatures 
Blocking Index

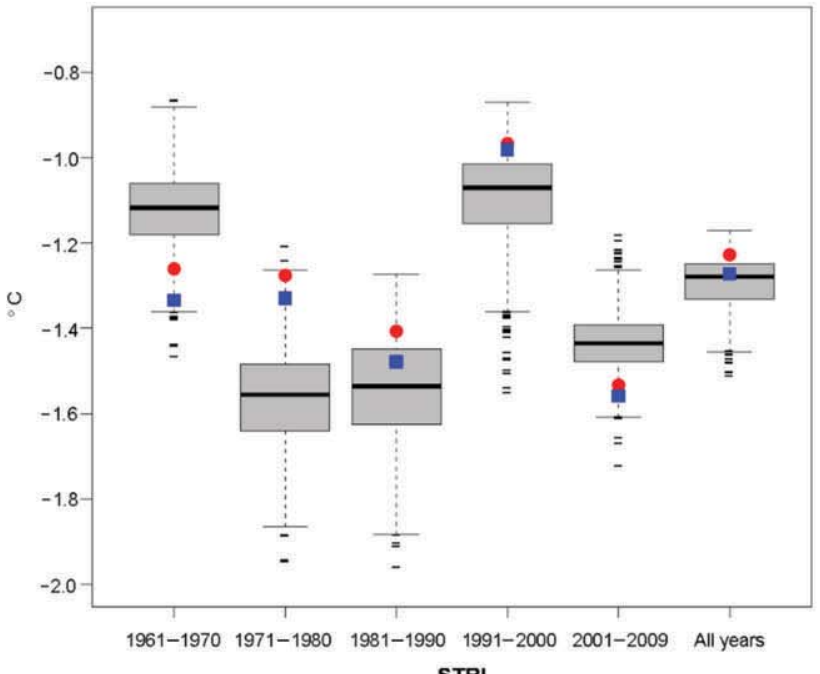

STRI

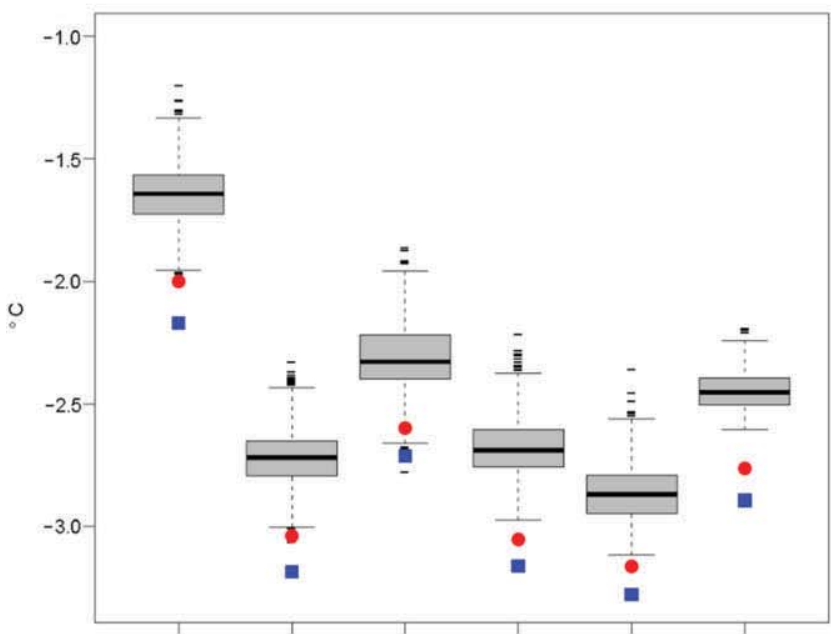

1961-1970 1971-1980 1981-1990 1991-2000 2001-2009 All years

$\mathrm{CO}_{2}$ forcing

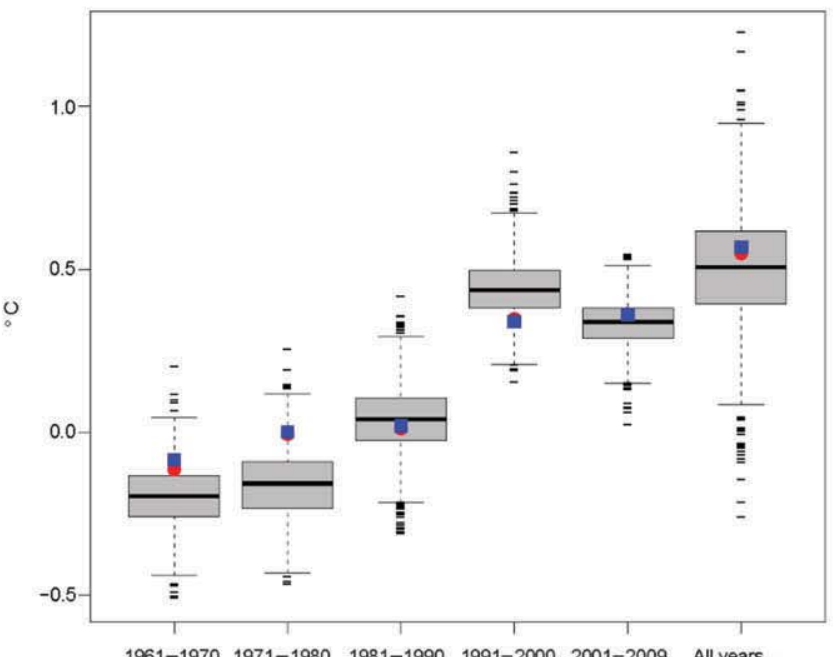

ENSO 3.4

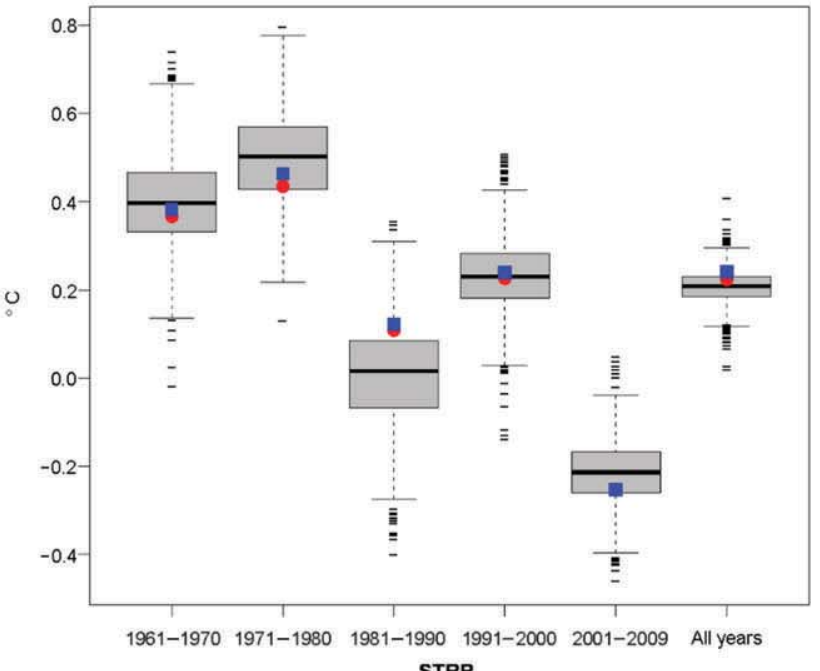

STRP

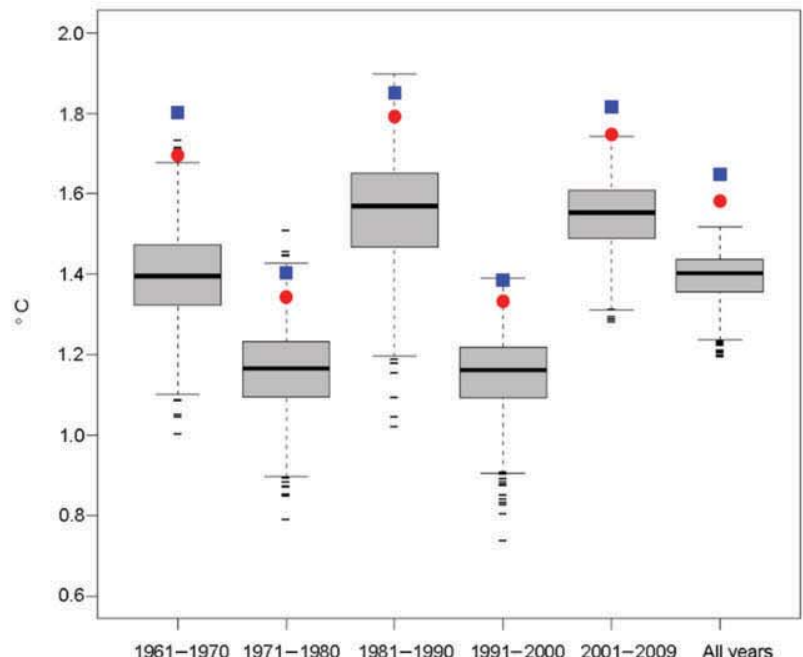

Solar forcing

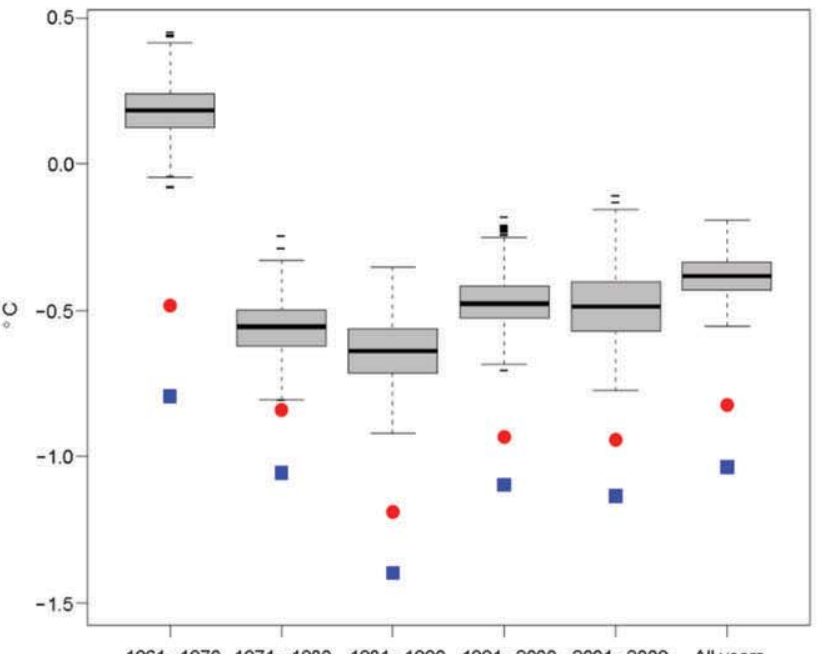

Figure 4. Distribution of the space-time model parameters for different decades starting from 1961-1970 to 2001-2009. Estimate for the full dataset (i.e. years 1961-2009) is given as the extreme right boxplot. The parameter estimates obtained from linear and additive models are superimposed as circle and square dots, respectively. 
Table 4. Different validation criteria for all 18 models we considered in this study, where LMd refers to the linear model, AMd the additive model and SMd the space-time model.

\begin{tabular}{|c|c|c|c|c|c|c|c|c|c|}
\hline \multirow[t]{2}{*}{ Years } & \multirow[t]{2}{*}{ Models } & \multicolumn{3}{|c|}{ All data } & \multicolumn{3}{|c|}{ Temperature data $<2{ }^{\circ} \mathrm{C}$} & \multirow[b]{2}{*}{$\begin{array}{c}\text { False alarm }(\%) \text { at } \\
2{ }^{\circ} \mathrm{C}\end{array}$} & \multirow[b]{2}{*}{$\begin{array}{l}\text { Hit rate }(\%) \\
\text { at } 2{ }^{\circ} \mathrm{C}\end{array}$} \\
\hline & & RMSE & MAE & MAPE & RMSE & MAE & MAPE & & \\
\hline \multirow[t]{3}{*}{$1961-1970$} & LMd & 3.94 & 3.14 & 41.94 & 5.01 & 4.47 & 39.68 & 80.71 & 88.27 \\
\hline & AMd & 3.77 & 3.01 & 40.67 & 4.78 & 4.22 & 38.83 & 76.90 & 88.08 \\
\hline & SMd & 2.11 & 1.61 & 23.56 & 1.81 & 1.38 & 35.19 & 28.36 & 93.99 \\
\hline \multirow[t]{3}{*}{$1971-1980$} & LMd & 3.84 & 3.09 & 44.32 & 4.82 & 4.36 & 65.56 & 82.26 & 89.30 \\
\hline & AMd & 3.68 & 2.97 & 43.62 & 4.53 & 4.06 & 68.24 & 79.61 & 89.10 \\
\hline & SMd & 2.28 & 1.73 & 23.18 & 2.16 & 1.64 & 53.20 & 34.89 & 93.46 \\
\hline \multirow[t]{3}{*}{$1981-1990$} & LMd & 3.61 & 2.88 & 47.28 & 4.46 & 3.95 & 111.27 & 75.98 & 91.44 \\
\hline & AMd & 3.45 & 2.76 & 45.86 & 4.19 & 3.67 & 107.97 & 71.99 & 91.37 \\
\hline & SMd & 2.16 & 1.65 & 26.24 & 1.83 & 1.37 & 74.77 & 33.72 & 94.48 \\
\hline \multirow[t]{3}{*}{$1991-2000$} & LMd & 4.05 & 3.25 & 43.94 & 5.29 & 4.77 & 43.84 & 82.30 & 89.07 \\
\hline & AMd & 3.87 & 3.12 & 41.99 & 5.05 & 4.52 & 38.87 & 79.08 & 89.00 \\
\hline & SMd & 1.99 & 1.50 & 21.96 & 1.59 & 1.17 & 36.14 & 21.80 & 94.62 \\
\hline \multirow[t]{3}{*}{$2001-2009$} & LMd & 4.16 & 3.30 & 49.92 & 5.11 & 4.43 & 85.98 & 77.92 & 87.89 \\
\hline & AMd & 3.96 & 3.15 & 48.49 & 4.80 & 4.12 & 84.88 & 74.28 & 87.95 \\
\hline & SMd & 2.46 & 1.88 & 27.35 & 1.82 & 1.46 & 46.48 & 31.55 & 93.07 \\
\hline \multirow[t]{3}{*}{ 1961-2009 } & LMd & 4.16 & 3.32 & 50.72 & 4.97 & 4.46 & 107.96 & 87.24 & 89.52 \\
\hline & AMd & 3.89 & 3.11 & 48.17 & 5.06 & 4.65 & 110.68 & 93.69 & 89.99 \\
\hline & SMd & 1.98 & 1.50 & 23.18 & 1.65 & 1.23 & 45.93 & 24.63 & 94.31 \\
\hline
\end{tabular}

(a) RMSE for all data

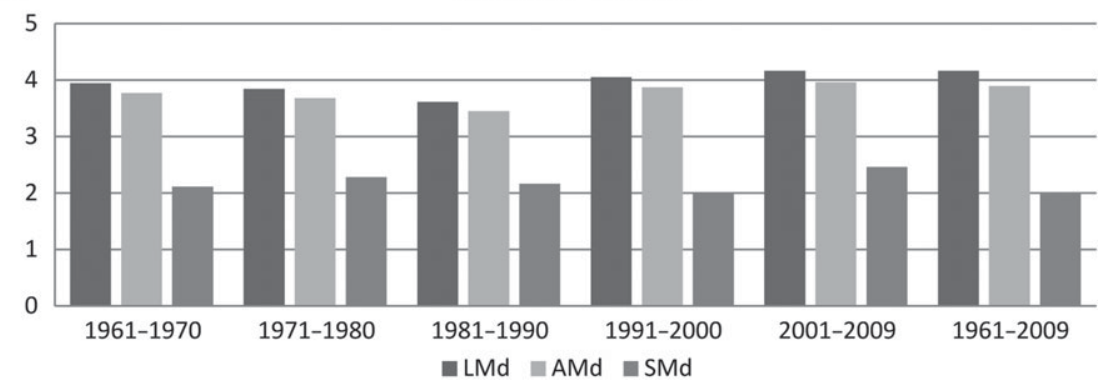

(b) RMSE for Tmin. $<2^{\circ} \mathrm{C}$

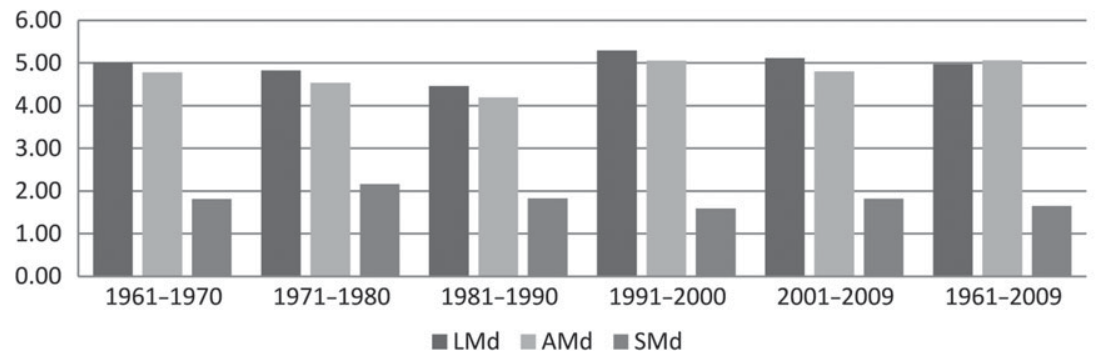

Figure 5. Root mean squared error (RMSE) criteria for spatial predictions for different models where in (a) all data and in (b) data with $T_{\min }<2{ }^{\circ} \mathrm{C}$ for the period 1961-2009.

of $0.4{ }^{\circ} \mathrm{C}(1961-1970), 0.53{ }^{\circ} \mathrm{C}(1971-1980), 0.08^{\circ} \mathrm{C}$ (1981-1990) and $0.23^{\circ} \mathrm{C}(1991-2000)$ (Figure 4).

In the case of the $\mathrm{CO}_{2}$ forcing covariate, increased levels of warming were simulated between successive decades except for the last (i.e. 2001-2009) with a slight decline in simulated warming over this period. This result is consistent with other analyses undertaken in the Australian region (Karoly and Braganza, 2005; Cai and Cowan, 2006; Preston and Jones, 2006) describing warming trends associated with increasing concentrations of GHGs.
The enhanced simulated decline in minimum temperatures, over the last decade, as a result of both the ENSO 3.4 and STRI covariates would suggest that both these drivers have been important in influencing the occurrence of extreme minimum temperature events over Australia. The increasing importance of the STRI, over the last decade, in influencing temperature variability, is consistent with findings by Timbal and Fawcett (2013) and Whan et al. (2014). As focussed on understanding the drivers of seasonal rainfall declines in southern Australia, the research of Timbal and Fawcett (2013) and Whan et al. 
(a)

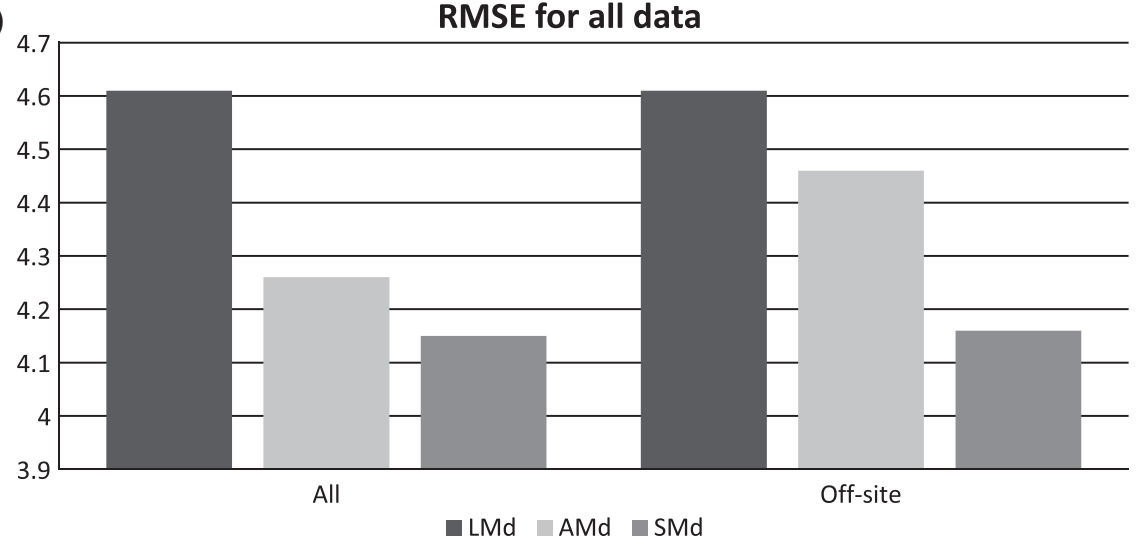

(b)

RMSE for Tmin $<2$ C

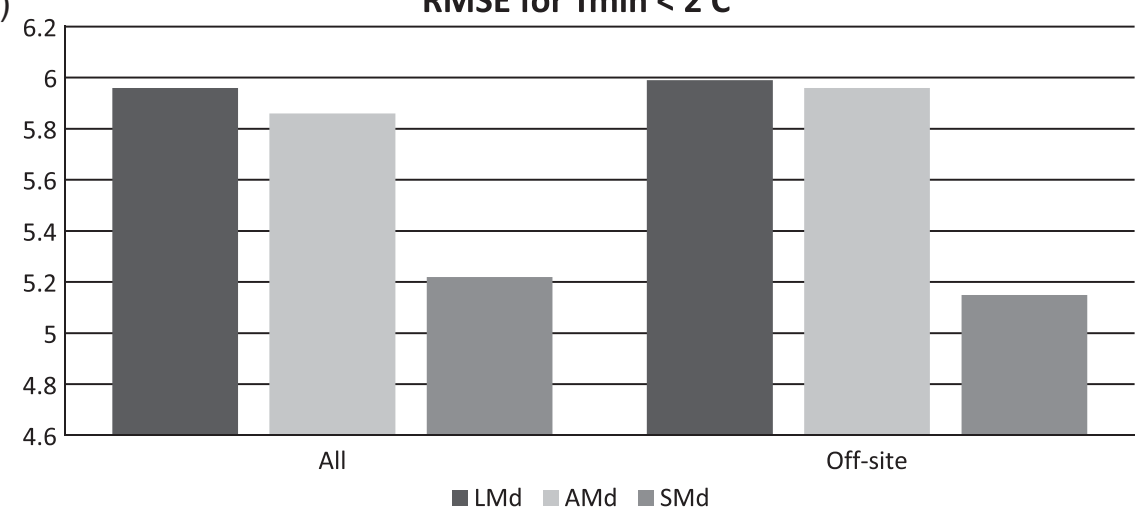

Figure 6. Root mean squared error (RMSE) criteria for temporal predictions for different models where in (a) all data and in (b) data with $T_{\text {min }}<2{ }^{\circ} \mathrm{C}$ are compared (i.e. years 1961-2009).

(2014) attributed rainfall declines since 1980 to an intensification of the subtropical ridge in this region. Their analyses showed a strengthening correlation between rainfall, the STRI and STRP post 1980. Most notably the STRI accounted for a greater proportion of rainfall variability than the position of the subtropical ridge (STRP). The findings from this article are consistent with these analyses.

With the exception of the early decade (i.e. 1961-1970), solar forcing has shown little change in correlation with minimum temperatures (Figure 4). This result is consistent with earlier work by Mann et al. (1998) in which the authors comment that "the correlation between solar irradiance and Northern Hemisphere temperatures has remained largely static after the mid-twentieth century' (Mann et al., 1998).

In the case of the BI, the consistent negative correlation with minimum temperatures infers that the greater the intensity of the blocking the more extreme the minimum temperatures will be. As with all the other correlations, these results have a strong physical basis, as strong blocking tends to slow the west to east passage of ridging highs as well as distort the synoptic feature in such a way as to increase the meridional exchange of energy (Pook et al., 2013).

\subsection{Comparison of the models for validation data}

Table 4 provides the validation criteria described in Section 2.5. From the pooled dataset containing observations from
1961 to 2009, the RMSE obtained from the linear model was 4.16, whereas from the additive model the RMSE was 3.89 (see Figure 5(a)). The slight improvement in predictive skill was introduced via the inclusion of station coordinates through the splining process. The RMSE is the lowest for the space-time model (i.e. 1.98), showing the considerable improvement in predictive skill due to the more complete consideration of the spatiotemporal random effect. This considerable improvement is also seen for the spatiotemporal model across each decade and for temperature extremes below $2^{\circ} \mathrm{C}$ data (Figure 5).

The MAE validation criteria showed similar results with the spatiotemporal model having values half that of the linear and additive models. The MAE values were consistently lower for the spatiotemporal model than for the other models across all decades and for extreme temperature values below $2{ }^{\circ} \mathrm{C}$ (Table 4 ).

The MAPE values were 50.72 and $48.17 \%$ for the linear and additive models, respectively, when considering the model performance across the entire period 1961-2009. The MAPE value for the space-time model was calculated as $23.18 \%$ which is half that of the linear and additive models (Table 4). This result implies that the space-time model was more likely to better predict temperatures than the other two approaches.

At the extreme end of the temperature distribution (i.e. below $2{ }^{\circ} \mathrm{C}$ ) the MAPE values were lowest for the spatiotemporal modelling approach (Table 4 ). The results 

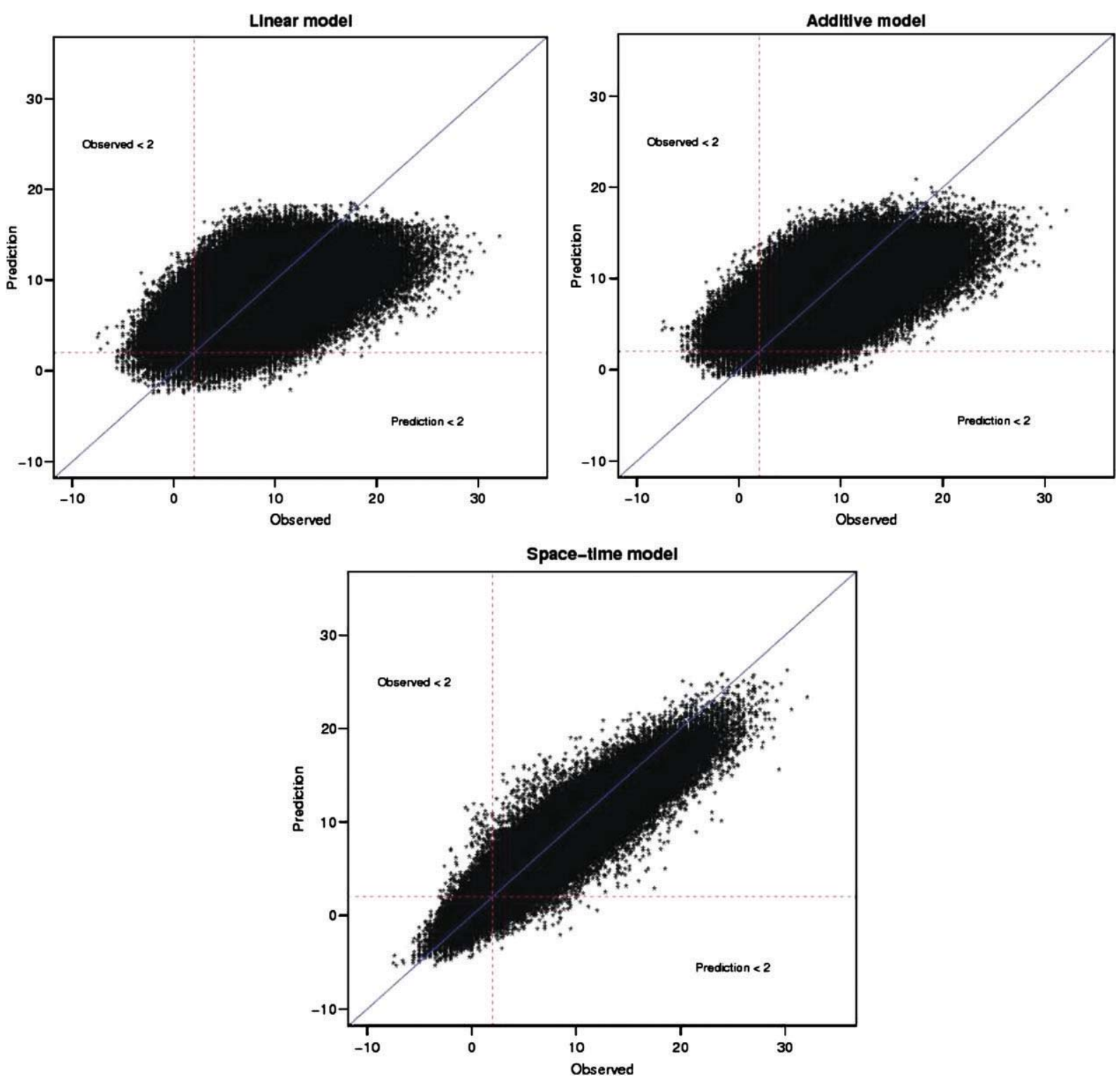

Figure 7. Observed versus predicted minimum temperature plots for linear, additive and space-time models using 1961-2009 dataset; $\boldsymbol{y}=\boldsymbol{x}$ line is superimposed in each plot. The threshold point for frost risk at $2{ }^{\circ} \mathrm{C}$ is also superimposed in the graphs.

indicate that the spatiotemporal modelling approach out-performs the other approaches for predicting frost occurrence.

In Table 4, we also provide the percentage of false alarms and hit rates for the predictions for all the 18 models. For a fixed threshold of $2{ }^{\circ} \mathrm{C}$, we observe for years 1961-2009, the hit rate of $94.31 \%$ for the space-time model compared with 89.9 and $89.5 \%$ for the other models.

The false alarm rates measure how poor each model was at predicting temperatures below $2{ }^{\circ} \mathrm{C}$. For the spatiotemporal model, the false alarm rate was $24.63 \%$ as opposed to $87.24-93.69 \%$ for the other two models.

Figure 6 shows RMSE scores obtained from the temporal predictions of the models. We set aside data from the decade 2001-2009 and fit the models using data from the 1961-2000 period. We compare the predictive results for all 75 locations and also for the set aside 25 locations for years 2001-2009. The validation statistics shows that the spatiotemporal model provides the best predictive results for all minimum temperature data (Figure 6(a)) as well as extreme values below $2^{\circ} \mathrm{C}$ (Figure 6(b)).

The validation results clearly demonstrate the enhanced skill and model performance of the spatiotemporal model over either the linear or additive model. It also demonstrates the importance of spatial dependency as both the spatiotemporal and the additive models often outperform the linear model.

In addition to the examination of the validation statistics we can also examine the distribution of observed versus predicted values for the entire period. Figure 7 clearly shows that the space-time model provides a much stronger linear relationship than the other two models, with significantly smaller bias at the extreme ends of the observed minimum temperatures. The plot of observed versus predicted values, produced via the spatiotemporal approach, shows much better agreement with the one-to-one line than 
for the other two approaches. This visualization would thus also support the superior performance of the spatiotemporal model (Figure 7).

\subsection{Predictive maps}

In this section, we produce predictive maps of frost frequency using the three modelling approaches. For prediction purposes, we define 253 grid points over our study region and obtained interpolated predicted values of the daily minimum temperature using data from the 75 monitoring locations. From these data, we impute the frequency of frosts in each month and year using $2{ }^{\circ} \mathrm{C}$ as the threshold for frosts. In this subsection, we show predictive maps for the month of August only in order to illustrate the significant spatial-temporal frost frequency changes.

\subsubsection{Comparison of the maps for different models}

We fitted the linear, additive and Bayesian space-time models to each month across the period 1961-2009 in order to impute the average monthly frost frequencies. Figure 8 shows the predicted mean spatial pattern of frost frequency for the month of August across the period 1961-2009. The values that appear on each of the maps represent the observed mean August frost numbers calculated for each of the recording stations in the case study region. Both the linear and additive models show regions with under prediction in the central and southeastern portions of the case study region (i.e. lower altitudes), showing predicted mean frost numbers approximately half of those observed (Figure 8).

The spatiotemporal model shows better agreement with observations across most of the case study region (i.e. at both the lower and high altitude locations). We apply the model to examine the decadal shifts in frost frequency across the entire study region and examine how anomalous the 2001-2009 period was in relation to the other decades in the observed record.

\subsubsection{Analysis of decadal changes in frost occurrence using Bayesian space-time models}

Figure 9 shows the decadal changes, against the base period 1961-1990, of average frost days for the month of August across the entire case study region. The spatial analysis shows that the mean number of August frosts has increased in the last two decades. This results from the frost risk tending to expand from the southeastern and eastern regions of the case study region towards the north and west. By the period 1991-2000, frost frequency had more than doubled for some lower altitude sites (Figure 9).

\section{Discussion}

In this study, we have analysed daily minimum temperatures across a case study region in Southeast Australia to identify the risk of frost occurrence in late winter and spring over the period from 1961 to 2009. For locations with elevation of $\leq 100 \mathrm{~m}$, there is a marked increase in the
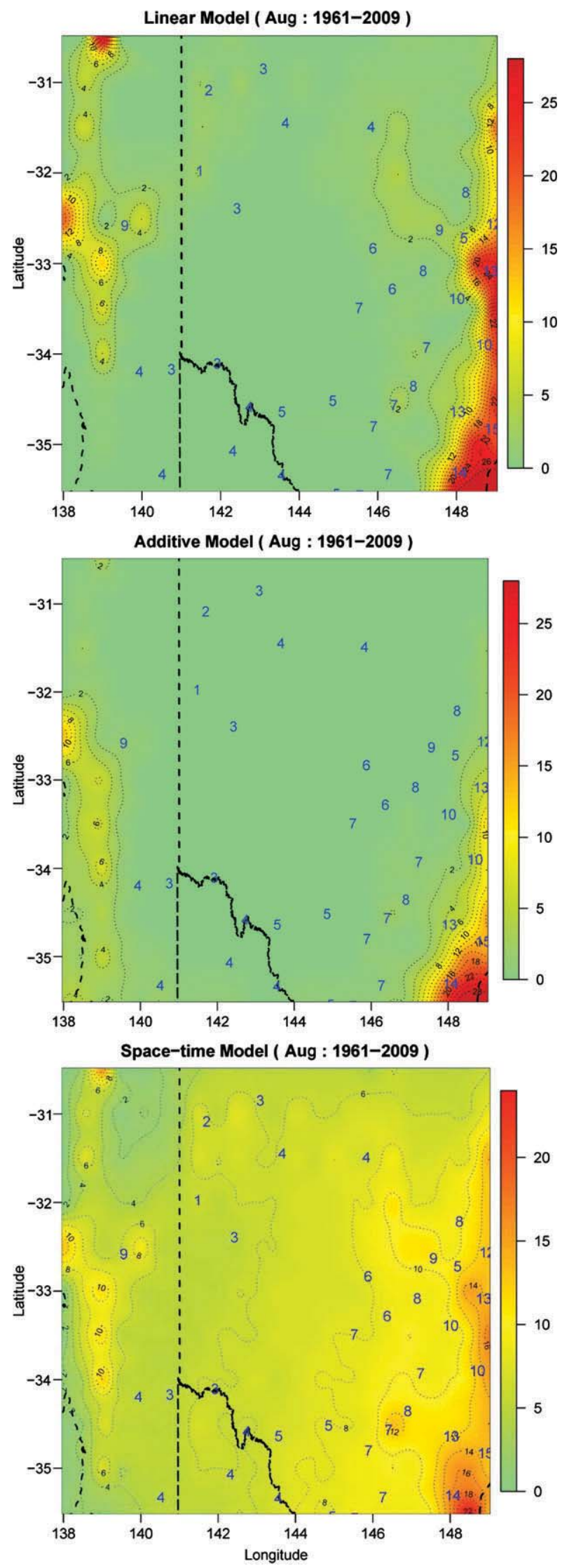

Figure 8. Prediction plots of the average number of frosts in August for years 1961-2009 using linear, additive and space-time models. Actual observations for frost levels are superimposed in the maps. 

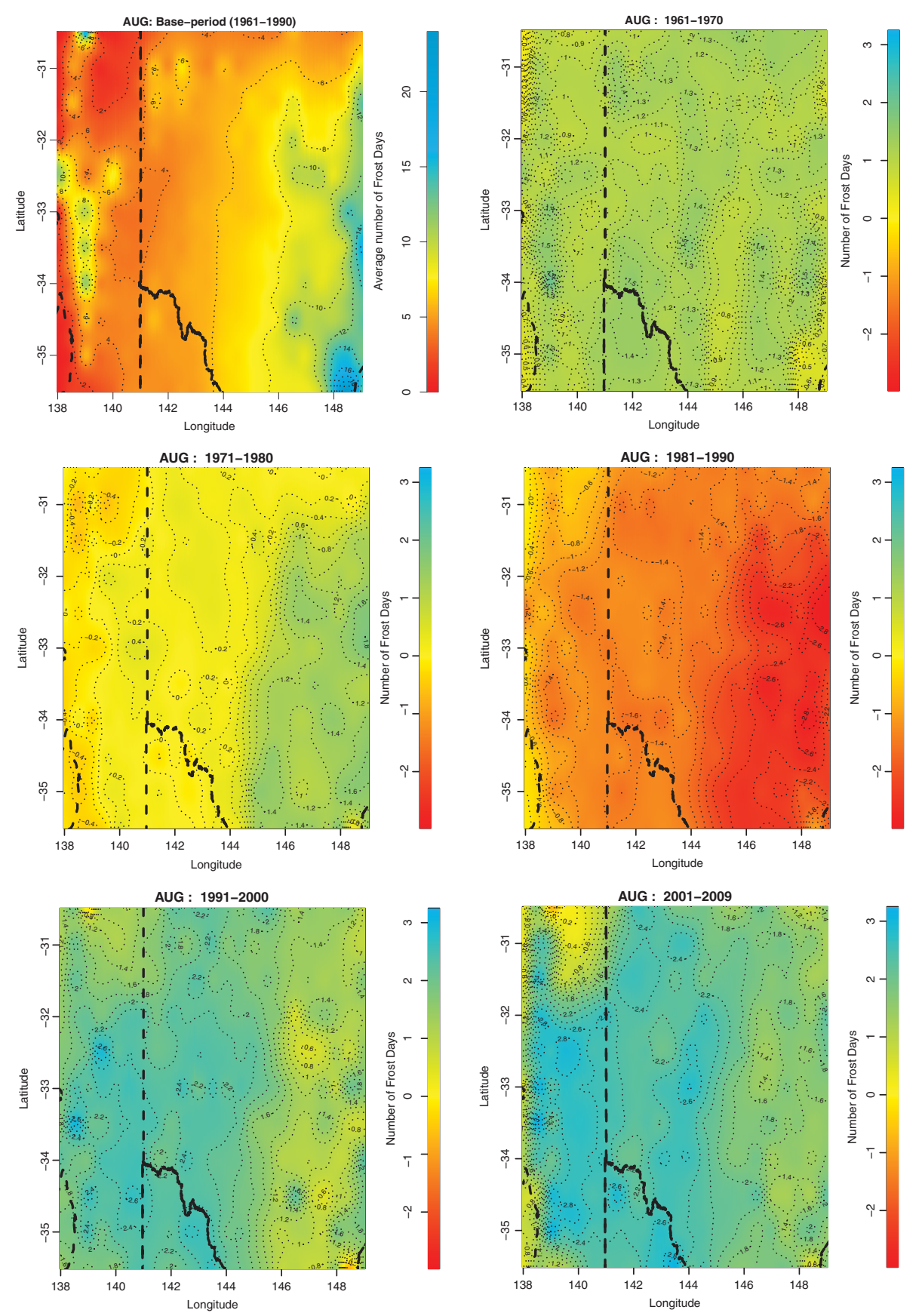

Figure 9. Spatial changes in frost levels are presented for each decade from 1961 to 2009 using the Bayesian space-time model for August. The top map includes mean August frost numbers for the period 1961-2009. The remaining maps represent the mean variation in frost days across respective decades. Values depicted on contour lines for the subsequent maps represent the frost anomaly measured in days.

mean number of frosts for the August-November period (with a statistically significant increase in August). This increase in frost numbers and shift in the period of occurrence is consistent with observations from other Southern Hemisphere locations (Collins et al., 2000; Pezza and Ambrizzi, 2005; Krishnamurti et al., 1999; Rusticucci and Vargas, 1995) but is paradoxical given the background global warming that has occurred over the same period (CSIRO, 2007; IPCC, 2012). The responses to possible occurrence of these 'climate change surprises' (Schneider and Root, 1996; Schneider et al., 1998; Rial et al., 2004) have been discussed previously and have given rise to the suggestion that managing the risks associated with climate change will require flexible strategies that can cope not only with the likely transient changes, but also region specific disturbances as well as large unforeseeable natural fluctuations (IPCC, 2012). The benefits of flexible approaches to changing historical frost risk have been demonstrated by Howden et al., 2003. Such an approach increased simulated gross margins by between 15 and $52 \%$, compared to using a fixed planting date (Howden et al., 2003). Similar flexible frost-risk strategies may increasingly be required in southeastern Australia. 
As $\mathrm{CO}_{2}$ forcing has been shown here to be an important and growing driver of change in minimum temperatures across the case study region, other drivers have also been identified in this study as contributing strongly to historical changes in frost risk.

Both ENSO (ENSO 3.4) and the STRI show a strengthening negative correlation with minimum temperatures over the last decade of analysis; suggesting a strong influence on minimum temperature variability over this period. In some instances this may continue to confound the effect of growing $\mathrm{CO}_{2}$ concentrations (Hegerl and Zwiers, 2011). Existing research already supports the long-term shift in latitudinal position and intensification of the band of high pressure typically located over southern central Australia and links this to anthropogenic warming (Larsen and Nicholls, 2009; Lu et al., 2007; Timbal and Murphy, 2007; Murphy and Timbal, 2008). This study links these synoptic system changes to increased frost risk. The ramifications of this shift in synoptic scale features include measurable declines in winter and spring rainfall (i.e. Wiedenmann et al., 2002; Hendon et al., 2007; Cai and Cowan, 2008; Timbal and Hope, 2008; Verdon-Kidd and Kiem, 2009) which will interact with the increased frost risk assessed here to impact negatively on agricultural production.

The position of the subtropical ridge was also found to be an important contributor to the pattern of minimum temperature occurrence, and while the pattern of influence varies considerably from decade to decade the parameter estimates show that its influence is increasingly important over the last decade. This is consistent with the findings of Timbal and Drosdowsky (2013).

When climate drivers such as rates of GHG emissions, as well as other solar radiation, the El Niño Southern Oscillation (ENSO 3.4) and STRP and STRI of subtropical highs and blocking high pressure systems are included in the Bayesian space-time modelling framework the resultant simulations, across the period 1960-2009, exhibit better validation statistics (e.g. 'false' alarm rates of $24.63 \%$ and 'hit' rates of $94.31 \%$ ) compared with alternative linear and additive statistical models. The validation statistics (i.e. RMSE and MAE metrics) were better for the space-time model than the others, when fitted across the whole period (i.e. 1961-2009), and for individual decades. The reproduction of the observed minimum temperature variability both temporally and spatially as well as the improved performance over existing statistical approaches would suggest that the spatial-temporal modelling approach will be useful for regional climate impact studies as well as supporting local and regional climate risk management activities (Haylock et al., 2006).

The mean number of August frosts has shown considerable decadal variation since 1961 with the most pronounced changes occurring in the southeastern and eastern regions (Figure 9). By the period 1991-2000, frost frequency had more than doubled for lower altitude sites. This poses ongoing and considerable risk to many agricultural industries (Anderson and Garlinge, 2000).

\section{References}

ABARE. 2007. Australian Commodity Statistics 2007. ABARE: Canberra.

Afanasev MM. 1966. Frost injury in wheat. Plant Dis. Rep. 50: 929-930. Alexander L, Hope P, Collins D, Trewin B, Lynch A, Nicholls N. 2006a. Trends in Australia's climate means and extremes: a global context. Aust. Meteorol. Mag. 56: 1-18.

Alexander LV, Zhang X, Peterson TC, Caesar J, Gleason B, Klein Tank AMG, Haylock M, Collins D, Trewin B, Rahimzadeh F, Tagipour A, Rupa Kumar K, Revadekar J, Griffiths G, Vincent L, Stephenson DB, Burn J, Aguilar E, Brunet M, Taylor M, New M, Zhai P, Rusticucci M, Vazquez-Aguirre JL. 2006b. Global observed changes in daily climate extremes of temperature and precipitation. J. Geophys. Res. 111: D05109, DOI: 10.1029/2005JD006290.

Allan RJ, Haylock MR. 1993. Circulation features associated with the winter rainfall decrease in southwestern Australia. J. Clim. 6(7): 1356-1367, DOI: 10.1175/1520-0442(1993)006<1356:CFAWTW $>2.0 . \mathrm{CO} ; 2$.

Anderson WK, Garlinge JR. 2000. The Wheat Book: Principles and Practice, Bulletin no. 4443. Department of Agriculture and Food, Western Australia \& Grains Research and Development Corporation, Western Australia. http://www.agric.wa. gov.au/objtwr/imported_assets/content/fcp/cer/wh/bulletin4443.pdf (accessed 5 August 2013)

Ashcroft MB, Chisholm LA, French KO. 2008. The effect of exposure on landscape scale soil surface temperatures and species distribution models. Landsc. Ecol. 23(2): 211-225, DOI: 10.1007/s10980007-9181-8.

Bakar KS, Sahu SK. 2013. spTimer: spatio-temporal Bayesian modelling using R. R package version 0.8. J. Stat. Softw. (in press). http://cran.r-project.org/web/packages/spTimer/ (accessed 13 May 2013)

Banerjee S, Carlin BP, Gelfand AE. 2004. Hierarchical Modeling and Analysis for Spatial Data. Chapman \& Hall/CRC: Boca Raton, FL.

Barnes EA, Slingo J, Woollings T. 2012. A methodology for the comparison of blocking climatologies across indices, models and climate scenarios. Clim. Dyn. 38(11-12): 2467-2481, DOI: 10.1007/s00382-011-1243-6.

Battisti DS, Naylor RL. 2009. Historical warnings of future food insecurity with unprecedented seasonal heat. Science 323(5911): 240-244, DOI: $10.1126 /$ science. 1164363.

Berrocal VJ, Gelfand AE, Holland DM. 2010. A spatio-temporal downscaler for output from numerical models. J. Agric. Biol. Environ. Stat. 15(2): 176-197, DOI: 10.1007/s13253-009-0004-z.

Berrocal VJ, Gelfand AE, Holland DM. 2012. Space-time data fusion under error in computer model output: an application to modeling air quality. Biometrics 68(3): 837-848, DOI: 10.1111/j.15410420.2011.01725.x.

Blennow K, Lindkvist L. 2000. Models of low temperature and high irradiance and their application to explaining the risk of seedling mortality. Forest Ecol. Manage. 135(1-3): 289-301.

Budong Q, Zhang X, Chen K, Feng Y, O'Brien T. 2010. Observed long-term trends for agroclimatic conditions in Canada. J. Appl. Meteorol. Climatol. 49: 604-618, DOI: 10.1175/2009JAMC2275.1.

Cai WJ, Cowan T. 2006. SAM and regional rainfall in IPCC AR4 models: can anthropogenic forcing account for southwest Western Australian winter rainfall reduction? Geophys. Res. Lett. 33: L24708, DOI: 10.1029/2006GL028037.

Cai WJ, Cowan TD. 2008. Dynamics of late autumn rainfall reduction over southeastern Australia. Geophys. Res. Lett. 35: L09708, DOI: 10.1029/2008GL033727.

Cai W, Shi G, Cowan T, Bi D, Ribbe J. 2005. The response of the southern annular mode, the East Australian Current, and the southern mid-latitude ocean circulation to global warming. Geophys. Res. Lett. 32: L23706, DOI: 10.1029/2005GL02470132.

Cashman G. 2000. Advection frost: a case study of the freeze of 27-28 October 1998 and its effects in the vineyards of the Canberra District. Aust. Grapegrow. Winemak. 438: 74-84.

Cattiaux J, Vautard R, Cassou C, Yiou P, Masson-Delmotte V, Codron F. 2010. Winter 2010 in Europe: a cold extreme in a warming climate. Geophys. Res. Lett. 37(20): L20704, DOI: 10.1029/2010GL044613.

Chang CP, Yongsheng Z, Tim L. 2000. Interannual and interdecadal variations of the east Asian summer monsoon and tropical pacific Sea-surface temperatures. Part 1: roles of the subtropical ridge. $J$. Clim. 13: 4310-4325, DOI: 10.1175/1520-0442\%282000\%29013 $<4310 \% 3$ AIAIVOT $>2.0 . \mathrm{CO} \% 3 \mathrm{~B} 2$. 
Chase TN, Knaff JA, Pielke RA, Kalnay E. 2003. Changes in global monsoon circulations since 1950. Nat. Hazards 29(2): 229-254, DOI: 10.1023/A:1023638030885.

Coleman W. 1992. A proposed winter-injury classification for apple trees on the northern fringe of commercial production. Can. J. Plant Sci. 72: 507-516, DOI: 10.4141/cjps92-064.

Collins D, Della-Marta P, Plummer N, Trewin B. 2000. Trends in annual frequencies of extreme temperature events in Australia. Aust. Meteorol. Mag. 49: 277-292.

Cressie NAC. 1993. Statistics for Spatial Data, Revised edn. Wiley: New York, NY.

Cressie NAC, Wikle CK. 2011. Statistics for Spatio-Temporal Data. Wiley: Hoboken, NJ.

CSIRO, Australian Bureau of Meteorology. 2007. Climate change in Australia: technical report 2007, CSIRO, Melbourne, Australia. 148 pp. http://www.climatechangeinaustralia. gov.au/technical_report.php (accessed 8 August 2012).

Davidson D. 1997. Frost and ways to minimise the risk. Aust. Grapegrow. Winemak. 403: 21-22.

Diggle P, Ribeiro PJ. 2007. Model-Based Geostatistics. Springer: New York, NY

Drosdowsky W. 2005. The latitude of the subtropical ridge over eastern Australia: the L index revisited. Int. J. Climatol. 25(10): 1291-1299, DOI: 10.1002/joc.1196.

Dukic V, Hayden M, Forgor AA, Hopson T, Akweongo P, Hodgson A, Monaghan A, Wiedinmyer C, Yoksas T, Thomson MC, Trzaska S, Pandya R. 2012. The role of weather in Meningitis Outbreaks in Navrongo, Ghana: a generalized additive modeling approach. J. Agric. Biol. Environ. Stat. 17(3): 442-460, DOI: 10.1007/s13253-0120095-9.

Fowler HJ, Blenkinsop S, Tebaldi C. 2007. Linking climate change modelling to impacts studies: recent advances in downscaling techniques for hydrological modelling. Int. J. Climatol. 27(12): 1547-1578, DOI: 10.1002/joc. 1556 .

Frederiksen JS, Frederiksen CS. 2007. Inter-decadal changes in southern hemisphere winter storm track modes. Tellus Ser. A Dyn. Meteorol. Oceanogr. 59: 599-617.

Frost AJ, Charles SP, Timbal B, Chiew FHS, Mehrotra R, Nguyen KC, Chandler RE, McGregor JL, Fu G, Kirono DGC, Fernandez E, Kent DM. 2011. A comparison of multi-site daily rainfall downscaling techniques under Australian conditions. J. Hydrol. 408(1-2): 1-18, DOI: 10.1016/j.jhydrol.2011.06.021.

Gelman A. 2004. Bayesian Data Analysis, 2nd edn. Chapman \& Hall/CRC: Boca Raton, FL.

Gelman A, Rubin DB. 1992. Inference from iterative simulation using multiple sequences. Stat. Sci. 7(4): 457-472.

Gohar LK, Shine KP. 2007. Equivalent $\mathrm{CO}_{2}$ and its use in understanding the climate effects of increased greenhouse gas concentrations. Weather 62: 307-311.

Harvey AC. 1989. Forecasting, Structural Time Series Models, and the Kalman Filter. Cambridge University Press: Cambridge, UK and New York, NY.

Hastie T, Tibshirani R. 1999. Generalized Additive Models. Chapman \& Hall/CRC: Boca Raton, FL.

Haylock MR, Cawley GC, Harpham C, Wilby RL, Goodess CM. 2006. Downscaling heavy precipitation over the UK: a comparison of dynamical and statistical methods and their future scenarios. Int. J. Climatol. 26(10): 1397-1415, DOI: 10.1002/joc.1318.

Hegerl G, Zwiers F. 2011. Use of models in detection and attribution of climate change. Interdiscip. Rev. Clim. Change 2: 570-591, DOI: $10.1002 /$ wcc. 121 .

Hendon HH, Thompson DWJ, Wheeler MC. 2007. Australian rainfall and surface temperature variations associated with the southern annular mode. J. Clim. 20: 2452-2467, DOI: 10.1175/JCLI4134.1.

Hodges JS, Reich BJ. 2010. Adding spatially-correlated errors can mess up the fixed effect you love. Am. Stat. 64(4): 325-334, DOI: 10.1198/tast.2010.10052.

Hoerling M, Eischeid J, Perlwitz J. 2010. Regional precipitation trends: distinguishing natural variability from anthropogenic forcing. J. Clim. 23(8): 2131-2145, DOI: 10.1175/2009JCLI3420.1.

Hope PK. 2006. Projected future changes in synoptic systems influencing southwest Western Australia. Clim. Dyn. 26: 765-780.

Howden SM, Meinke H, Power B, McKeon GM. 2003. Risk management of wheat in a non-stationary climate: frost in Central Queensland. In: Integrative modelling of biophysical, social and economic systems for resource management solutions, Post DA (ed). MSSANZ Inc.: Canberra, 17-22.
Hughes L. 2003. Climate change and Australia: trends, projections and impacts. Aust. Ecol. 28(4): 423-443, DOI: 10.1046/j.1442-9993.2003.01300.x.

IPCC. 2012. Managing the risks of extreme events and disasters to advance climate change adaptation. In A Special Report of Working Groups I and II of the Intergovernmental Panel on Climate Change, Field CB, Barros V, Stocker TF, Qin D, Dokken DJ, Ebi KL, Mastrandrea MD, Mach KJ, Plattner G-K, Allen SK, Tignor M, Midgley PM (eds). Cambridge University Press: Cambridge, UK, 582 pp.

Jones PD, Lister DH, Osborn TJ, Harpham C, Salmon M, Morice CP. 2012. Hemispheric and large-scale land-surface air temperature variations: an extensive revision and an update to 2010. J. Geophys. Res. 117: DO5127, DOI: 10.1029/2011JD017139.

Kalma JD, Laughlin GP, Caprio JM, Hamer PJC. 1992. Advances in Bioclimatology, 2: The Bioclimatology of Frost. Springer-Verlag: Berlin, 144 pp.

Karoly DJ, Braganza K. 2005. Attribution of recent temperature changes in the Australian region. J. Clim. 18: 457-464, DOI: 10.1175/JCLI-3265.1.

Karoly DJ, Wu Q. 2005. Detection of regional surface temperature trends. J. Clim. 18: 4337-4343, DOI: 10.1175/JCLI3565.1.

Kivinen S, Kaarlejarvi E, Jylha K, Raisanen J. 2012. Spatiotemporal distribution of threatened high-latitude snowbed and snow patch habitats in warming climate. Environ. Res. Lett. 7(3): 1-9, DOI: 10.1088/1748-9326/7/3/034024.

Kokic P, Crimp S, Howden M. 2011. Forecasting climate variables using a mixed-effect state-space model. Environmetrics 22(3): 409-419, DOI: $10.1002 /$ env.1074.

Krige DG. 1951. A statistical approach to some basic mine valuation problems on the Witwatersrand. J. Chem. Metallurg. Mining Soc. S. Afr. 52(6): 119-139.

Krishnamurti TN, Tewari M, Chakraborty DR, Marengo J, Silva PL, Satyamurty P. 1999. Downstream amplification: a possible precursor to major freeze events over southeastern Brazil. Weather Forecast. 14: 242-270, DOI: 10.1175/1520-0434(1999)014<0242: DAAPPT $>2.0 . \mathrm{CO} ; 2$.

Larsen SH, Nicholls N. 2009. Southern Australian rainfall and the subtropical ridge: Variations, interrelationships, and trends. Geophys. Res. Lett. 36: L08708, DOI: 10.1029/2009GL037786.

Levy PE, Cannell MGR, Friend AD. 2004. Modelling the impact of future changes in climate, $\mathrm{CO} 2$ concentration and land use on natural ecosystems and the terrestrial carbon sink. Glob. Environ. Change Hum. Policy Dimens. 14(1): 21-30, DOI: 10.1016/j.gloenvcha.2003. 10.005 .

Livingston JE, Swinbank JC. 1950. Some factors influencing the injury to winter wheat heads by low temperatures. Agron. J. 42: 153-157.

Lu J, Vecchi GA, Reichler T. 2007. Expansion of the Hadley cell under global warming. Geophys. Res. Let. 34: L06805, DOI: $10.1029 / 2006$ GL028443.

Mann ME, Bradley RS, Hughes MK. 1998. Global-Scale Temperature Patterns and Climate Forcing Over the Past Six Centuries. Nature 392: 779-787, DOI: $10.1038 / 33859$.

McGowan HA, Marx SK, Soderholm J, Denholm J. 2010. Evidence of solar and tropical-ocean forcing of hydroclimate cycles in southeastern Australia for the past 6500 years. Geophys. Res. Lett. 37: L10705, DOI: $10.1029 / 2010$ GL042918.

Murphy B, Timbal B. 2008. A review of recent climate variability and climate change in south-eastern Australia. Int. J. Climatol. 28(7): 859-879, DOI: 10.1002/joc.1627.

Myhre G, Highwood EJ, Shine KP, Stordal F. 1998. New estimates of radiative forcing due to well mixed greenhouse gases. Geophys. Res. Lett. 25: 2715-2718, DOI: 10.1029/98GL01908.

Nicholls N. 2010. Local and remote causes of the southern Australian autumn-winter rainfall decline, 1958-2007. Clim. Dyn. 34: 835-845, DOI: 10.1007/s00382-009-0527-6.

Nicholls N, Drosdowsky W, Lavery B. 1996. Australian rainfall variability and change. Weather 52: 66-72.

O'Neill BF, Bond K, Tyner A, Sheppard R, Bryant T, Chapman J, Bell J, Donnelly A. 2012. Climatic change is advancing the phenology of moth species in Ireland. Entomol. Exp. Appl. 143(1): 74-88, DOI: 10.1111/j.1570-7458.2012.01234.x.

Passioura J. 2007. The drought environment: physical, biological and agricultural perspectives. J. Exp. Bot. 58: 113-117, DOI: 10.1093/ jxb/erl212.

Paulsen G, Heyne E. 1983. Grain production of winter wheat after spring freeze injury. Agron. J. 75: 705-707.

Pezza AB, Ambrizzi T. 2005. Dynamical conditions and synoptic tracks associated with different types of cold surges over tropical South America. Int. J. Clim. 25: 215-241, DOI: 10.1002/joc.1080. 
Pezza AB, Simmonds I. 2005. The first South Atlantic hurricane: unprecedented blocking, low shear and climate change. Geophys. Res. Lett. 32(15): L15712, DOI: 10.1029/2005GL023390.

Plummer N, Salinger MJ, Nicholls N, Suppiah R, Hennessy KJ, Leighton RM, Lough JM. 1999. Changes in climate extremes over the Australian region and New Zealand during the twentieth century. In Weather and Climate Extremes. Springer: The Netherlands, 183-202.

Pook MJ, Gibson T. 1999. Atmospheric blocking and storm tracks during SOP-1 of the FROST Project. Aust. Meteorol. Mag. 48: 51-60, Special edition.

Pook MJ, Risbey J, McIntosh P, Ummenhofer C, Marshall A, Meyers G. 2013. The seasonal cycle of blocking in the Australian region and its relationship with rainfall. Mon. Weather Rev. 141: 4534-4553.

Porter JR, Gawith M. 1999. Temperatures and the growth and development of wheat: a review. Eur. J. Agron. 10: 23-36.

Pouteau R, Rambal S, Ratte JP, Goge F, Joffre R, Winkel T. 2011 Downscaling MODIS-derived maps using GIS and boosted regression trees: the case of frost occurrence over the arid Andean highlands of Bolivia. Remote Sens. Environ. 115(1): 117-129, DOI: 10.1016/j.rse.2010.08.011.

Preston BL, Jones RN. 2006. Climate Change Impacts on Australia and the Benefits of Early Action to Reduce Global Greenhouse Gas Emissions. CSIRO: Melbourne, Australia, $41 \mathrm{pp}$

R-Development-Core-Team. 2006. R: A Language and Environment for Statistical Computing. R Foundation for Statistical Computing: Vienna.

Rial J, Pielke S Sr, Beniston RA, Claussen M, Canadell M, Cox J, Held P, De Noblet-Ducoudré H. 2004. Nonlinearities, feedbacks and critical thresholds within the Earth's climate system. Clim. Change 65: 11-38, DOI: 10.1023/B:CLIM.0000037493.89489.3f.

Risbey JS, Pook MJ, McIntosh PC, Wheeler MC, Hendon HH. 2009. On the remote drivers of rainfall variability in Australia. Mon. Weather Rev. 137: 3233-3253.

Rogiers S. 1999. Frost injury and cold hardiness in grapes. Aust. Grapegrow. Winemak. 432: 13-18.

Rusticucci M, Vargas W. 1995. Synoptic situations related to spells of extreme temperatures over Argentina. J. Appl. Meteorol. 2: 291-300, DOI: $10.1002 /$ met.5060020401.

Sahu SK, Bakar KS. 2012a. A comparison of Bayesian models for daily ozone concentration levels. Stat. Methodol. 9(1-2): 144-157, DOI 10.1016/j.stamet.2011.04.009.

Sahu SK, Bakar KS. 2012b. Hierarchical Bayesian auto-regressive models for large space time data with applications to ozone concentration modelling by Sujit Kumar Sahu and Khandoker Shuvo Bakar: rejoinder. Appl. Stoch. Models Bus. Ind. 28(5): 418-419.

Sahu SK, Gelfand AE, Holland DM. 2007. High-resolution space-time ozone modeling for assessing trends. J. Am. Stat. Assoc. 102(480) 1221-1234, DOI: 10.1198/016214507000000031.

Sahu SK, Yip S, Holland DM. 2009. Improved space-time forecasting of next day ozone concentrations in the eastern US. Atmos. Environ. 43(3): 494-501, DOI: 10.1016/j.atmosenv.2008.10.028.

Sakai A, Larcher W. 1987. Frost Survival of Plants. Springer-Verlag. Berlin.

Schneider SH, Root TL. 1996. Ecological implications of climate change will include surprises. Biodivers. Conserv. 5: 1109-1119.

Schneider SH, Turner BL II, Garriga HM. 1998. Imaginable surprise in global change science. J. Risk Res. 1(2): 165-185, DOI: 10.1080/136698798377240.

Schubert S. 1998. Downscaling local extreme temperature changes in south-eastern Australia from the CSIRO Mark2 GCM. Int. J. Climatol. 18(13): 1419-1438.

Single W. 1964. Studies on frost injury to wheat. II. Ice formation within the plant. Aust. J. Agric. Res. 15: 869-875.

Stone RC, Nicholls N, Hammer G. 1996. Frost in northeast Australia: trends and influences of phases of the Southern Oscillation. J. Clim. 9: $1896-1909$

Timbal B, Arblaster JM. 2006. Land cover change as an additional forcing to explain the rainfall decline in the south west of Australia. Geophys. Res. Lett. 33: L07717, DOI: 10.1029/2005GL025361 ISBN: 0094-8276.
Timbal B, Drosdowsky W. 2013. The relationship between the decline of Southeastern Australian rainfall and the strengthening of the subtropical ridge. Int. J. Climatol. 33: 1021-1034, DOI: 10.1002/joc.3492.

Timbal B, Fawcett R. 2013. A historical perspective on southeastern Australian rainfall since 1865 using the instrumental record. J. Clim. 26: $1112-1129$.

Timbal B, Hope P. 2008. Observed early winter mean seal level pressure changes above southern Australia: a comparison of existing datasets. CAWCR Res. Lett. 1: 1-7. http://www.cawcr. gov.au/publications/researchletters/CAWCRResLets1.pdf (accessed 1 August 2013)

Timbal B, Murphy B. 2007. Observed climate change in South-East of Australia and its relation to large-scale modes of variability. BMRC Res. Lett. 6: 6-11. http://www.bom.gov.au/bmrc/ pubs/researchletter/reslett_06.pdf (accessed 1 August 2013).

Tong SL, Wang XY, Guo YM. 2012. Assessing the short-term effects of heatwaves on mortality and morbidity in Brisbane, Australia: comparison of case-crossover and time series analyses. Plos One 7(5). http://www.plosone.org/article/info\%3Adoi\%2F10.1371\%2Fjournal. pone.0037500 (accessed 1 August 2013).

Trewin BC. 2012. Techniques used in developing the Australian Climate Observations Reference Network - Surface Air Temperature (ACORN-SAT) dataset. CAWCR Technical Report 49. Centre for Australian Weather and Climate Research, Melbourne, 92 pp. http://cawcr.gov.au/publications/ technicalreports/CTR_049.pdf (accessed 1 August 2013).

Ummenhofer CC, Gupta AS, Briggs PR, England MH, McIntosh PC, Meyers GA, Pook MJ, Raupach MR, Risbey JS. 2011. Indian and Pacific Ocean influences on southeast Australian drought and soil moisture. J. Clim. 24: 1313-1336, DOI: 10.1175/2010JCLI3475.1.

Vaneckova P, Beggs PJ, Jacobson CR. 2010. Spatial analysis of heat-related mortality among the elderly between 1993 and 2004 in Sydney, Australia. Soc. Sci. Med. 70(2): 293-304, DOI: 10.1016/j.socscimed.2009.09.058

Verdon-Kidd DC, Kiem AS. 2009. Nature and causes of protracted droughts in southeast Australia: comparison between the Federation, WWII, and Big Dry Droughts. Geophys. Res. Lett. 36: L22707, DOI: 10.1029/2009GL041067.

Verdon-Kidd DC, Kiem AS, Moran R. 2013. Links between the Big Dry in Australia and hemispheric multi-decadal climate variability-implications for water resource management. Hydrol. Earth Syst. Sci. Discuss. 10: 13539-13593, DOI: 10.5194/hessd-10-135392013 .

Wang J, Wang EL, Liu DL. 2011. Modelling the impacts of climate change on wheat yield and field water balance over the Murray-Darling Basin in Australia. Theor. Appl. Climatol. 104(3-4): 285-300, DOI: 10.1007/s00704-010-0343-2.

Whan K, Timbal B, Lindesay J. 2014. Linear and nonlinear statistical analysis of the impact of sub-tropical ridge intensity and position on south-east Australian rainfall. Int. J. Climatol. 34: 326-342, DOI: 10.1002/joc.3689.

Wiedenmann JM, Lupo AR, Mokhov II, Tikhonova EA. 2002. The climatology of blocking anticyclones for the Northern and Southern Hemisphere: blocking intensity as a diagnostic. J. Clim. 15: 3459-3473, DOI: 10.1175/1520-0442(2002)015<3459:TCOBAF $>$ 2.0.CO;2.

Woldendorp G, Hill MJ, Doran R, Ball MC. 2008. Frost in a future climate: modelling interactive effects of warmer temperatures and rising atmospheric $\mathrm{CO}_{2}$ on the incidence and severity of frost damage in a temperate evergreen (Eucalyptus pauciflora). Glob. Change Biol. 14: 294-308, DOI: 10.1111/j.1365-2486.2007.01499.x.

Wood SN. 2006. Generalized Additive Models : An Introduction with R. Chapman \& Hall/CRC: Boca Raton, FL.

Wood S. 2012. Mixed GAM Computation Vehicle with GCV/AIC/REML Smoothness Estimation 1.7-22. R Development Core Team, CRAN. http://www.unej.ac.id/pdf/cran/mgcv.pdf (accessed 31 March 2013).

Zhang Y, Bi P, Hiller J. 2008. Climate variations and salmonellosis transmission in Adelaide, South Australia: a comparison between regression models. Int. J. Biometeorol. 52(3): 179-187, DOI: 10.1007/s00484-007-0109-4. 